\title{
Dynamic properties of water in breast pathology depend on the histological compounds: distinguishing tissue malignancy by water diffusion coefficients
}

Rustem F Baikeev ${ }^{1 *}$, Roman A Gubanov², Kamil K Sadikov², Sufiya Z Safina², Farhat F Muhamadiev and Timur A Sibgatullin ${ }^{3}$

\begin{abstract}
Background: The parameters that characterize the intricate water diffusion in tumors may also reveal their distinct pathology. Specifically, characterization of breast cancer could be aided by diffusion magnetic resonance. The present in vitro study aimed to discover connections between the NMR biexponential diffusion parameters [fast diffusion phase $\left(D_{\text {FDP }}\right)$, slow diffusion phase $\left(D_{S D P}\right)$, and spin population of fast diffusion phase $\left(P_{1}\right)$ ] and the histological constituents of nonmalignant (control) and malignant human breast tissue. It also investigates whether the diffusion coefficients indicate tissue status.
\end{abstract}

Methods: Post-surgical specimens of control (mastopathy and peritumoral tissues) and malignant human breast tissue were placed in an NMR spectrometer and diffusion sequences were applied. The resulting decay curves were analyzed by a biexponential model, and slow and fast diffusion parameters as well as percentage signal were identified. The same samples were also histologically examined and their percentage composition of several tissue constituents were measured: parenchyma (P), stroma (St), adipose tissue (AT), vessels (V), pericellular edema (PCE), and perivascular edema (PVE). Correlations between the biexponential model parameters and tissue types were evaluated for different specimens. The effects of tissue composition on the biexponential model parameters, and the effects of histological and model parameters on cancer probability, were determined by non-linear regression.

Results: Meaningful relationships were found among the in vitro data. The dynamic parameters of water in breast tissue are stipulated by the histological constituents of the tissues (P, St, AT, PCE, and V). High coefficients of determination $\left(R^{2}\right)$ were obtained in the non-linear regression analysis: $D_{F D P}\left(R^{2}=0.92\right), D_{S D P}\left(R^{2}=0.81\right)$, and $P_{1}\left(R^{2}=0.93\right)$.

In the cancer probability analysis, the informative value $\left(R^{2}\right)$ of the obtained equations of cancer probability in distinguishing tissue malignancy depended on the parameters input to the model. In order of increasing value, these equations were: cancer probability $(P, S t, A T, P C E, V)\left(R^{2}=0.66\right)$, cancer probability $\left(D_{F D P}, D_{S D P}\right)\left(R^{2}=0.69\right)$, cancer probability $\left(D_{F D P}, D_{S D P}, P_{1}\right)\left(R^{2}=0.85\right)$.

Conclusion: Histological tissue components are related to the diffusion biexponential model parameters. From these parameters, the relative probability of cancer in a given specimen can be determined with some certainty.

Keywords: Breast cancer, NMR, Self-diffusion coefficient, Morphology, $\mathrm{H}_{2} \mathrm{O}$, Non-linear regression analysis

\footnotetext{
*Correspondence: baikeev@hotmail.com

'Department of Biochemistry, Kazan State Medical University, Butlerova St.,

49, Kazan, Tatarstan, Russia

Full list of author information is available at the end of the article
}

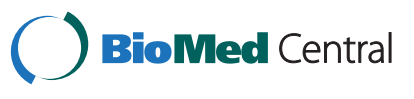

(c) 2014 Baikeev et al.; licensee BioMed Central Ltd. This is an Open Access article distributed under the terms of the Creative Commons Attribution License (http://creativecommons.org/licenses/by/2.0), which permits unrestricted use, distribution, and reproduction in any medium, provided the original work is properly credited. The Creative Commons Public Domain Dedication waiver (http://creativecommons.org/publicdomain/zero/1.0/) applies to the data made available in this article, unless otherwise stated. 


\section{Background}

Cancer diagnoses proceed in several steps, each with varying reliability (\%): (1) Revelation of paraneoplastic clinical syndromes $(30-40 \%)$, (2) Positive values of laboratory immunochemical markers (30- 40\%; 75 - 84\% in advanced cases), and (3) Histological revelation (9597\%). Histological diagnosis is based on appearance of atypical cells and tissues, amount of mitosis, the state of the tumor's boundaries and surrounding tissues and whether the tumor has invaded the vessels through the basal membrane - cancer in situ.

Non-invasive (objective) detection and diagnosis of breast cancer is essential for successful treatment. Magnetic resonance (MR) has become an increasingly popular technique for detecting and delineating breast cancer in everyday practice.

MR theory attempts to relate MR signal parameters to the microstructural and physiological features of tissues, enabling a non-invasive nosological diagnosis, especially of cancer.

Diffusion (self-diffusion) is the process by which molecules or ions are randomly shifted (Brownian motion) under the action of internal thermal energy. Intracellular water exists in both "free" and "bound" states, which are easily distinguished by the time of NMR $-{ }^{1} \mathrm{H}\left(\mathrm{T}_{1}\right.$ and $\left.\mathrm{T}_{2}\right)$ relaxation. Aqueous ion, protein, lipid and nucleotides systems are known to hold "hydration water" at their interfaces. Unlike regular water, which freezes around $0^{\circ} \mathrm{C}$, hydration water remains fluid down to $\sim 200 \mathrm{~K}\left(-73^{\circ} \mathrm{C}\right)$. ${ }^{17} \mathrm{O}$ data show that hydration water is less mobile than free water and undergoes anisotropic motions [1].

Self-diffusion between the two water phases (two domains) can occur by molecular transfer, or may be triggered by the $\mathrm{pH}$ conditions. In the latter case, the mean residence time of a water molecule is of the order of $10^{-3} \mathrm{~s}$ at room temperature and $\mathrm{pH} 7$ [2]. Intracellular water moves chiefly by Brownian displacement; cytoplasmic streaming plays at most a minimal role [3].

Nuclear Magnetic Resonance (NMR) is useful for studying the static properties of matter (i.e. structure) and its dynamic properties such as self-diffusion, flow and relaxation.

The pulsed field gradient (PFG) NMR method, pioneered by Stejskal and Tanner [4], remains one of the main techniques for obtaining dynamic information such as self-diffusion coefficients.

The displacement sensitivity of PFG NMR is approximately $100 \mathrm{~nm}$ and diffusion coefficients can be measured down to approximately $10^{-14} \mathrm{~m}^{2} \mathrm{~s}^{-1}$ [5]. Therefore, PFG NMR is an excellent tool for probing molecular diffusion and structure in biological systems, and is especially convenient because it requires no labeled probe molecules. The theory behind the PFG method has been welldeveloped [6]. Briefly, the Hahn spin-echo pulse sequence is modified into a PFG spin-echo pulse sequence, in which each period $(\tau)$ is spiked with a "rectangular" magnetic field gradient pulse of duration $\delta$ and magnitude g. The separation $t_{d}$ between the leading edges of the gradient pulses specifies the time over which diffusion is measured. If the spin moves along the direction of the field gradient during $t_{d}$, the phase change induced by the first gradient pulse is not cancelled by the phase change induced by the second identical gradient pulse. Averaged over a spin ensemble, this phase shifting effect diminishes the signal. The extent of diminution is proportional to the net displacement of the spin along the direction of the gradient during $t_{\mathrm{d}}$. The apparent diffusion coefficient (ADC), which need not equal the true coefficient, is frequently determined from the initial slope of the attenuation plot. Variations in the experimental conditions are usually quantified by the value of $b=\gamma^{2} \delta^{2} g^{2} t_{d}$.

In studies of water diffusion in biological systems, any specific NMR attenuation curve may be modelled by a broad range of mathematical functions: biexponential, multiexponential and nonexponential.

Scientists have long sought the physical cause of the biexponentiality of the diffusion signal decay function. The problem of self-diffusion coefficient measurements during interphase exchange was first resolved by Kärger [7]. They assumed a biphasic system in which the exponential function distribution depends on the lifetime of the kinetic unit in the two phases. They fitted the diffusion decay $A\left(t_{d}\right)$ record as a function of $t_{d}$. However, this model does not account for the restricted diffusion through biological membranes (cell and organelle boundaries), or the relaxation time difference between the two domains. These limitations have been discussed in relation to diffusion in the brain [8]. Price modified [9] Kärger's model to accurately quantify water diffusion, but this model is limited to spherical interfaces such as isolated human breast cancer cells in culture [10].

Models based on dynamic parameters (such as membrane restriction and permeability) [11] and geometrical features (such as planes and cylinders) [12] have also been proposed. In all of these diverse models, the diffusion signal decay is well-approximated by a biexponential function [13].

Currently, researchers accept two ways of describing NMR diffusion decay in complex biomedical samples and tissues, even when the detailed morphology of the sample is unknown.

The first approach considers tissue as a simple bicompartmental model comprising extracellular and intracellular spaces. In this model, the apparent diffusion coefficient $\left(\mathrm{ADC}_{\mathrm{m}}\right)$ is obtained from the volume-weighted quantities $\mathrm{V}_{\mathrm{SDP}}$ (the intracellular slow diffusion phase (SDP) of water) and $\mathrm{V}_{\mathrm{FDP}}$ (the extracellular fast diffusion phase (FDP) of water), and the average intracellular and 
extracellular diffusion coefficients $\left(\mathrm{D}_{\mathrm{SDP}}\right.$ and $\mathrm{D}$ FDP, respectively) in slow exchange [14]. The ADC is then computed as $\mathrm{ADC}_{\mathrm{m}}=\left(\mathrm{V}_{\mathrm{SDP}} \mathrm{D}_{\mathrm{SDP}}+\mathrm{V}_{\mathrm{FDP}} \mathrm{D}_{\mathrm{FDP}}\right) /\left(\mathrm{V}_{\mathrm{SDP}}+\right.$ $\mathrm{V}_{\mathrm{FDP}}$ ) (1).

The second approach is based on diffusion NMR observations; namely, that diffusion in biological tissues is well-fitted to a biexponential function corresponding to a slow diffusion phase (SDP) and a fast diffusion phase (FDP) in slow exchange: $\mathrm{S}=\mathrm{S}_{0} \mathrm{P}_{1} \exp \left(-\mathrm{bD}_{\mathrm{FDP}}\right)+\mathrm{S}_{0} \mathrm{P}_{2} \exp$ $\left(-b_{\mathrm{SDP}}\right)(2)$ [15]. Here, $\mathrm{S}$ is the MRI signal at a particular b value, $S_{0}$ is the signal at $\mathbf{b}=0$, and $D_{F D P}$ and $D_{S D P}$ are the diffusion coefficients in the fast and slow diffusion phases respectively, with $\mathrm{P}_{1(\mathrm{FDP})}+\mathrm{P}_{2(\mathrm{SDP})}=1$.

In fact, the estimated diffusion coefficients and volume fractions of the SDP and FDP have been strikingly consistent across the literature [10,16-18].

Based on the data accumulated in NMR studies, scientists have quantitatively differentiated malignant tissues by evaluating their diffusion coefficients [19]. DW (diffusion-weighted) MRI provides significant opportunities for accurately assessing how breast cancer patients respond to neoadjuvant chemotherapy at an early stage, since it enables voxel-based image analysis [20]. Consequently, evaluating the dynamic state of water in cancerous breast tissues is important for determining the degree of a neoplasm process. Thus, the MRI values related to tumor cellularity can be used to differentiate malignant breast lesions from benign ones.

A mean diffusivity (MD) threshold of $1.1 \times 10^{-9} \mathrm{~m}^{2} / \mathrm{s}$ discriminates malignant from benign breast lesions with a specificity and sensitivity of $81 \%$ and $80 \%$, respectively [21]. In the same study, a cut-off of $1.31 \times$ $10^{-9} \mathrm{~m}^{2} / \mathrm{s}$ (MD of malignant lesions $-2 \mathrm{SD}$ ) reduced the specificity to $67 \%$, but achieved $100 \%$ sensitivity [21]. The cut-off requirement [22] is a distinct disadvantage of this approach in cancer diagnosis, since it is relative and depends on the biochemical constituents of the patient's own tissues [23]. These constituents influence the morphology and anisotropic diffusion properties of breast tissues [24,25]. The MR scanner system $[21,26]$, magnetic field strength $[21,27,28]$, acquisition sequence $[19,26]$, b-value $[27,29,30]$, fat suppression method [31] should also be considered.

The present in vitro study aimed to discover connections between the NMR biexponential diffusion parameters and the histological constituents of the nonmalignant (control) and malignant human breast tissues. It also seeks to distinguish breast tissue status from the measured water diffusion coefficients.

\section{Methods}

Seventeen female patients with breast pathology were recruited for this study; six control subjects (mastopathy, peritumoral areas) and eleven breast cancer patients
$\left(\mathrm{T}_{2} \mathrm{~N}_{0} \mathrm{M}_{0}, n=6 ; \mathrm{T}_{2} \mathrm{~N}_{1} \mathrm{M}_{0}, n=5\right)$. The mean age of the cancer patients was $(59 \pm 4)$ years, and mean cancer duration was 65 days (range 10-125 days). The inflammatory symptoms were as follows: pain (3 patients), erythema ( 2 patients), heat (1 patient); one patient reported a family history of breast cancer. Single specimens $(\approx 1 \mathrm{~cm} \times$ $0.5 \mathrm{~cm} \times 0.5 \mathrm{~cm}, \approx 0.25$ gram) were excised from the operation tissue of each patient and preserved for examination $(n=17)$. Samples were maintained at $275-277 \mathrm{~K}\left(2-4^{\circ} \mathrm{C}\right)$ until required. Abundance of fat was an exclusion criterion for specimens.

NMR examination was performed in vitro two hours after the operation, applying the "stimulated echo" method [32], without spinning of the specimens. The self-diffusion and relaxation times $\left(\mathrm{T}_{1}\right.$ and $\left.\mathrm{T}_{2}\right)$ of water and organic compounds in the tissues were determined by a ${ }^{1} \mathrm{H}-\mathrm{NMR}$ analyzer "Spin Track" (Resonance Systems Ltd., YoshkarOla, Russia) operating at $19.1 \mathrm{MHz}$ and equipped with the electromagnet. The maximal amplitude of the magnetic field gradient pulse g was set to $4 \mathrm{~T}$ (Tesla) $/ \mathrm{m}$. The diffusion attenuation of the spin echo signal, that is, the dependence of the echo amplitude $\mathrm{A}(\mathrm{g})$ on the gradient pulse amplitude in the coordinates, is revealed in the $\ln [\mathrm{A}(\mathrm{g}) / \mathrm{A}(0)]$ versus $\mathrm{b}$ plot presented in Figure 1, where $\mathrm{b}=\gamma^{2} \delta^{2} \mathrm{~g}^{2} \mathrm{t}_{\mathrm{d}}$ (the diffusion time $t_{d}$ is $\left.20 \mathrm{~ms}\right), A(0)$ is the echo amplitude in the absence of a magnetic field gradient, $\mathrm{g}_{0}=1 \times 10^{-3} \mathrm{~T} \cdot \mathrm{m}^{-1}, \gamma$ is the gyromagnetic ratio for protons, and $\delta=0.2 \mathrm{~ms}$ is the pulse duration; $2 \tau=20 \mathrm{~ms}, \pi / 2=8 \mu \mathrm{s}$. The repetition time is $2 \mathrm{~s}$. The mean $\mathrm{ADC}\left(\mathrm{ADC}_{\mathrm{m}}\right)$ depends on both $\mathrm{D}_{\mathrm{FDP}}$ and $\mathrm{D}_{\mathrm{SDP}}$, which quantity was investigated to enable comparison of our data with the results of in vivo experiments and the $\mathrm{ADC}_{\mathrm{m}}$ values among different sample groups. The $\mathrm{ADC}_{\mathrm{m}}$ was determined from the initial slope of the attenuation plot $\mathrm{A}(\mathrm{g})$ (Figure 1 ) as $\mathrm{ADC}_{\mathrm{m}}=-1 / \mathrm{t}_{\mathrm{d}} \cdot(\partial \ln [\mathrm{A}$ $\left.(\mathrm{g}) / \mathrm{A}(0)] / \partial(\gamma \delta \mathrm{g})^{2}\right)\left.\right|_{\gamma \delta \mathrm{g} \rightarrow 0}$. The slope of the function $\mathrm{A}(\mathrm{g})$

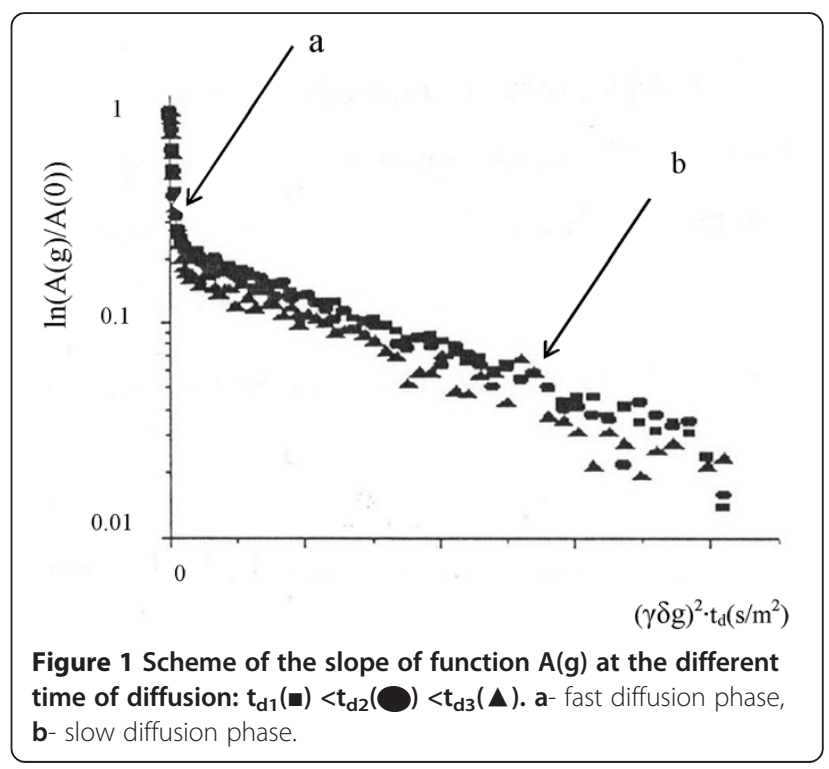


was approximated by a programmed version of the "peeloff" method [33]. In this presentation, the self-diffusion coefficients ( $D_{\text {FDP }}$ and $\mathrm{D}_{\mathrm{SDP}}$ ) are determined by the tangent to the angle of the exponential decay curves of the function A (g) (Figure 1).

Under the experimental conditions of the present study, diffusion was derived from the apparent (not the true) values of $\mathrm{ADC}_{\mathrm{m}}, \mathrm{D}_{\mathrm{FDP}}$ and $\mathrm{D}_{\mathrm{SDP}}$. The dependence of $\mathrm{ADC}$ on $\mathrm{t}_{\mathrm{d}}(n=3)$ in the peritumoral breast tissue specimens was examined separately, with $t_{d}=11,50$, 200 , or $800 \mathrm{~ms}$.

Measurements were performed at $(310 \pm 0.2) \mathrm{K}[(37 \pm$ $0.2)^{\circ} \mathrm{C}$. A water $\left(\mathrm{H}_{2} \mathrm{O}\right.$; Sigma-Aldrich Corp., St. Louis, MO, USA) sample was used as a standard. At $303 \mathrm{~K}\left(30^{\circ} \mathrm{C}\right)$, water attenuation was described by a single exponential diffusion decay; namely, by $\mathrm{A}(\mathrm{g}) / \mathrm{A}(0)=\exp (-\mathrm{kD})$, where $\mathrm{D}$ is independent of $t_{d}$ and equal to $2.7 \times 10^{-9} \mathrm{~m}^{2} / \mathrm{s}$.

Once the NMR studies were complete, the breast tissue specimens were immersed in formaldehyde and their histology was examined. The time elapsed between tissue excision during the operation and fixation of the specimens was approximately 2 hours. The percentages of relevant histological constituents, namely, parenchyma (P), stroma (St), adipose tissue (AT), vessels (V), pericellular edema (PCE), and perivascular edema (PVE), were calculated by the "net of random step" method [34] and measured as relative units (\%). Different groups of tissue specimens were statistically compared by the Wilcoxon rank-sum test [35]. Correlation (Spearman's coefficient) and multiple non-liner regression analyses were performed using Statgraphics Centurion XV Professional (USA). Data were fitted to a second-order regression equation [35]:

$$
\mathrm{y}=b_{0}+\sum_{j=1}^{k-1} b_{j} x_{j}+\sum_{1=l+1}^{k} b_{j l} x_{j} \cdot x_{l}+\sum_{j=+}^{k} b_{j j} \cdot x_{j}^{2}
$$

This study was approved by the local ethics committee of Kazan State Medical University (protocol No.3,
04.04.2012). Written informed consent was obtained from all participants prior to the study.

\section{Results and discussion}

Morphology: agreement between in vivo and in vitro NMR studies

Analyses were conducted according to the TNM classification and stroma contents (Tables 1 and 2). Female patients at tumor stage $\mathrm{T}_{2 \mathrm{~A}}$ or $\mathrm{T}_{2 \mathrm{~B}}$ only were selected for the study, for the following reasons: (1) In the Republic of Tatarstan (Russia) 63.33\% of women undergoing treatment in oncological clinics are hospitalized at stage $\mathrm{T}_{2} \mathrm{~N}_{(0,1,2)} \mathrm{M}_{0}$ [36]; (2) Restricting the tumor stage ensured a homogeneous cohort for the study.

Instances of mastopathy and fibroadenoma in the control group were of the pericanalicular type, with concentric proliferation of the intralobular connecting tissue around channels. Tissue anomalies were restricted in size. Some of the cancer specimens were scirrhous, and hyalinization of the connecting tissue impregnated with small groups of tumorous cells was observed. In most cases, adenocarcinoma was classified among the infiltrative carcinomas. Tubular or solid glandular-like structures were located in the thick connecting tissue (Figure 2, A-D). The P, AT, PCE and V parameters were significantly different $(p<0.05)$ among different groups (Table 1$)$.

Our analysis first investigates whether the results of the in vitro experiments accord with those obtained in vivo. NMR measurements in vivo and in vitro reflect the vitality and proton relaxation characteristics of the tissues [2,37]. Nevertheless, in vitro diffusion studies are important because they provide biochemical and biophysical information that reflects the state of malignant tissues. By contrast, because in vivo diffusion studies average the ADC, they exclude information on the FDP and SDPs of water (diffusion coefficients and spin populations) [38-40].

Table 1 Morphometry features (share,\%) of the mammary gland tissue samples

\begin{tabular}{lcccccc}
\hline Diagnosis & Parenchyma & Stroma & Adipose tissue & PCE & PVE & Vessels \\
\hline 1. Control $n=6$ & 1.1. & 1.2. & 1.3. & 1.4. & 1.5. & 1.6. \\
& $16,7 \pm 19,7^{1}$ & $35,7 \pm 8,8$ & $32,6 \pm 21,0$ & $4,0 \pm 6,4$ & $5,9 \pm 5,8$ & $5,1 \pm 4,9$ \\
& $(0,01-54,7)^{2}$ & $(25,5-49,0)$ & $(0,01-53,8)$ & $(0,01-17,0)$ & $(0,01-13,6)$ & $(0,2-14,1)$ \\
& $5470^{3}$ & 1,9 & 5380 & 1700 & 1360 & 70,5 \\
2. Breast cancer $n=11$ & 2.1. & 2.2. & 2.3. & 2.4. & 2.5. & $7,5 \pm 11,1$ \\
& $30,7 \pm 15,7$ & $39,9 \pm 13,6$ & $11,6 \pm 16,1$ & $7,1 \pm 6,9$ & $3,1 \pm 2,6$ \\
& $(10,3-56,6)$ & $(26,1-64,2)$ & $(0,01-50,4)$ & $(0,01-16,0)$ & $(0,01-32,3)$ & $(0,1-7,3)$ \\
& 5,5 & 2,5 & 5040 & 1600 & 3230 & 73 \\
\hline
\end{tabular}

Note: $\mathrm{n}$ - number of the samples; ${ }^{1}$ - mean value $\pm \mathrm{SD},{ }^{2}$ - range of parameter; ${ }^{3}$ - ratio of high/low range values of the certain morphological constituents percentage. Comparison of 2 groups (Wilcoxon): 1.1-2.1 $\mathrm{p}<0,028$ 1.4-2.4 $\mathrm{p}<0,047$.

1.2-2.2 $p>0,6$ 1.5-2.5 $p>0,17$.

$1.3-2.3 p<0,0471.6-2.6 p<0,047$. 
Table 2 Self-diffusion coefficients of the water molecules in breast cancer

\begin{tabular}{|c|c|c|c|c|c|c|}
\hline \multirow[t]{3}{*}{ Parameter } & \multirow[t]{2}{*}{$\begin{array}{l}\text { Control } \\
n=6\end{array}$} & \multicolumn{3}{|l|}{ Breast cancer } & \multicolumn{2}{|c|}{$\begin{array}{l}\text { Share of stroma }{ }^{*}(\%) \\
\text { (control + cancer) }\end{array}$} \\
\hline & & The entire group of cancer specimens $n=11$ & $\mathrm{~T}_{2} \mathrm{~N}_{0} \mathrm{M}_{0} \mathrm{n}=6$ & $\mathrm{~T}_{2} \mathrm{~N}_{1} \mathrm{M}_{0} \mathrm{n}=5$ & $<50 n=14$ & $\geq 50 \mathrm{n}=3$ \\
\hline & 1 & 2 & 3 & 4 & 5 & 6 \\
\hline \multirow[t]{3}{*}{$\mathrm{ADC}_{\mathrm{m}} \cdot 10^{-9}\left(\mathrm{~m}^{2} / \mathrm{s}\right)$} & $0,78 \pm 0,28^{1}$ & $1,62 \pm 1,28$ & $0,85 \pm 0,34$ & $2,54 \pm 1,30$ & $0,91 \pm 0,28$ & $3,25 \pm 0,75$ \\
\hline & $(0,41-1,16)^{2}$ & $(0,33-3,43)$ & $(0,33-1,22)$ & $(0,79-3,43)$ & $(0,41-1,35)$ & $(0,33-3,43)$ \\
\hline & $2,84^{3}$ & 10,39 & 3,69 & 4,34 & 3,30 & 10,39 \\
\hline \multirow[t]{3}{*}{$\mathrm{D}_{\mathrm{FDP}} \cdot 10^{-9}\left(\mathrm{~m}^{2} / \mathrm{s}\right)$} & $1,25 \pm 0,13$ & $0,97 \pm 0,25$ & $0,93 \pm 0,24$ & $1,01 \pm 0,28$ & $1,06 \pm 0,27$ & $1,10 \pm 0,18$ \\
\hline & $(1,10-1,40)$ & $(0,57-1,25)$ & $(0,60-1,20)$ & $(0,57-1,29)$ & $(0,57-1,40)$ & $(0,90-1,20)$ \\
\hline & 1,27 & 2,19 & 2,00 & 2,25 & 2,46 & 1,34 \\
\hline \multirow[t]{3}{*}{$P_{1 \text { (share) }}$} & $0,48 \pm 0,17$ & $0,75 \pm 0,22$ & $0,74 \pm 0,28$ & $0,78 \pm 0,14$ & $0,69 \pm 0,24$ & $0,53 \pm 0,26$ \\
\hline & $(0,27-0,77)$ & $(0,23-0,97)$ & $(0,23-0,97)$ & $(0,63-0,95)$ & $(0,27-0,97)$ & $(0,23-0,72)$ \\
\hline & 2,84 & 4,23 & 4,22 & 1,51 & 3,59 & 3,14 \\
\hline \multirow[t]{3}{*}{$\mathrm{D}_{\mathrm{SDP}} \cdot 10^{-11}\left(\mathrm{~m}^{2} / \mathrm{s}\right)$} & $1,67 \pm 0,15$ & $0,86 \pm 0,68$ & $1,75 \pm 0,17$ & $2,00 \pm 1,03$ & $1,69 \pm 0,16$ & $2,30 \pm 1,34$ \\
\hline & $(0,50-1,91)$ & $(0,40-3,84)$ & $(1,50-1,98)$ & $(1,40-3,84)$ & $(1,40-1,98)$ & $(1,50-3,84)$ \\
\hline & 3,82 & 9,6 & 1,32 & 2,74 & 1,41 & 2,56 \\
\hline
\end{tabular}

Note: $\mathrm{n}$ - number of the samples; ${ }^{1}$ - mean value $\pm S D,{ }^{2}$ - range of parameter.; ${ }^{3}$ - ratio of high/low range values of the certain diffusion parameter.

*- crosslinked collagen is embedded into the carbohydrate matrix of stroma.

Comparison of 2 groups (Wilcoxon):

$A D C_{m}: 1-2 p<0,03 ; D_{F D P}: 1-2 p<0,05 ; P_{1}: 1-2 p>0,15 ; D_{S D P}: 1-2 p>0,9 ; 1-3 p>0,9 ; 1-3 p<0,05 ; 1-3 p>0,15 ; 1-3 p>0,3 ; 1-4 p>0,7 ; 1-4 p>0,05 ; 1-4 p<0,05 ; 1-4 p=1 ; 1-5$ $p>0,7 ; 1-5 p>0,5 ; 1-5 p>0,05 ; 1-5 p=1 ; 1-6 p=1 ; 1-6 p>0,5 ; 1-6 p>0,2 ; 1-6 p=1 ; 3-4 p>0,2 ; 3-4 p>0,8 ; 3-4 p>0,8 ; 3-4 p>0,5 ; 5-6 p=1 ; 5-6 p>0,5 ; 5-6 p>0,1 ; 5-6 p=1$.

The absolute ADC values (in units of $10^{-9} \mathrm{~m}^{2} / \mathrm{s}$ ) obtained in vivo for malignant mass have been reported as $0.95 \pm 0.18$ [21], $0.97 \pm 0.20$ [19], $0.99 \pm 0.18$ [27], $1.03 \pm$ 0.02 [28], 1.021 [26], $1.17 \pm 0.24$ [41], and $1.22 \pm 0.31$ [42]). The ADC values of benign masses were reported as $1.47 \pm 0.21$ [27], $1.48 \pm 0.37$ [21], 1.488 [26], $1.57 \pm 0.23$ [19] and $1.67 \pm 0.54$ [42]), while those of cysts were $2.25 \pm$ 0.26 [21] and 2.64 [27], and those of normal tissues - were $1.85 \pm 0.22$ [27] and $2.09 \pm 0.27$ [42]. These ranges include the in vitro $\mathrm{ADC}_{\mathrm{m}}$ s reported in Table 2.

Among the wide ADC range reported in the literature $\left[(0.664-1.359) \times 10^{-9} \mathrm{~m}^{2} / \mathrm{s}\right][43], 30 \%$ and $70 \%$ of breast cancer lesions were characterized by $\mathrm{ADC}>1.44 \times$ $10^{-9} \mathrm{~m}^{2} / \mathrm{s}$ and ADC $\leq 1.44 \times 10^{-9} \mathrm{~m}^{2} / \mathrm{s}$, respectively [44]. Our data (Table 2) reveal the cause of this discrepancy. We found that most of the biological tissue parameters are non-parametric; that is, they cannot be approximated by a standard data distribution function (such as normal, Gaussian, exponential). Consequently, their standard deviation is large relative to the mean. Second, breast tissues are characterized by high morphological spatial heterogeneity (Table 1; Figure 2).

The current literature establishes no reliable ranges of the absolute ADCs of breast cancer tissues. The $\mathrm{ADC}$ of pure mucinous breast carcinoma is $(1.8 \pm$ $0.4) \times 10^{-9} \mathrm{~m}^{2} / \mathrm{s}$ [45]. Compared with inflammatory breast diseases, the ADC in breast cancers is lower at the wall $\left(1.09 \times 10^{-9} \mathrm{~m}^{2} / \mathrm{s}\right.$ vs. $\left.1.42 \times 10^{-9} \mathrm{~m}^{2} / \mathrm{s}\right)$ and higher in the central region of the tumor $\left(1.94 \times 10^{-9} \mathrm{~m}^{2} / \mathrm{s}\right.$ vs. $\left.1.05 \times 10^{-9} \mathrm{~m}^{2} / \mathrm{s}\right)$. In the central region of an invasive ductal carcinoma, the ADC was reported as $2.7 \times$ $10^{-9} \mathrm{~m}^{2} / \mathrm{s}$ [38].

\section{Diffusion coefficients reflect the compartmentalization of water in tissues}

MR studies of intracellular water generally require that the intracellular and extracellular water signals be clearly distinguished.

The difference between the intracellular and extracellular water states in the NMR- ${ }^{1} \mathrm{H}$ range of the spin-echo decay structure is complicated, but may be described by the biphasic diffusion model with interface exchange (see Eq. (2) [15] in the background, Figure 1 and Table 3).

The FDP and SDP volume fractions (70\% and 30\% respectively; see Table $\left.2, \mathrm{P}_{1}=48-75 \%\right)$ disagree with the volume fractions of the extra- and intracellular compartments [46]. Therefore, the FDP and the SDP cannot be directly assigned to these physical compartments. However, experimental evidence exists that the volume variations of the SDP and FDP highly correlate with the volume variations of the intra- and extracellular spaces as cells enlarge or shrink under different physiological, pathological or experimental conditions $[47,48]$.

This mismatch could be partially attributable to the extracellular space occupied by various structures, 


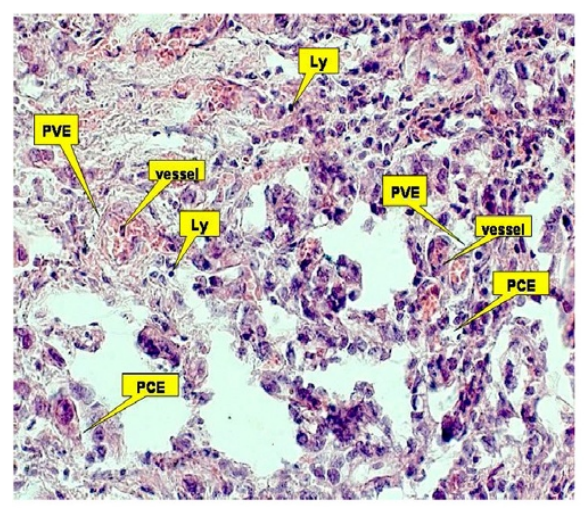

A

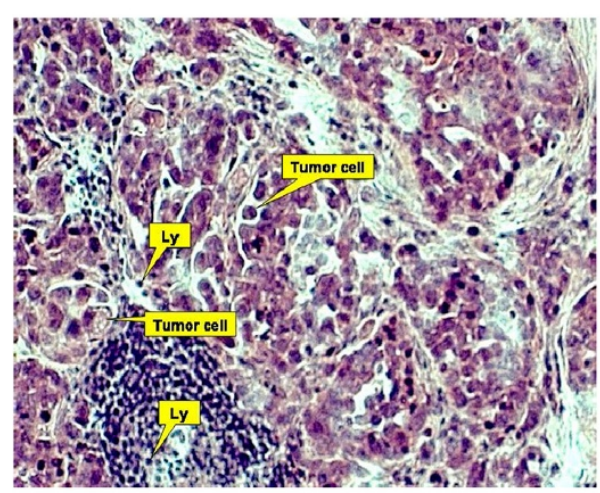

C

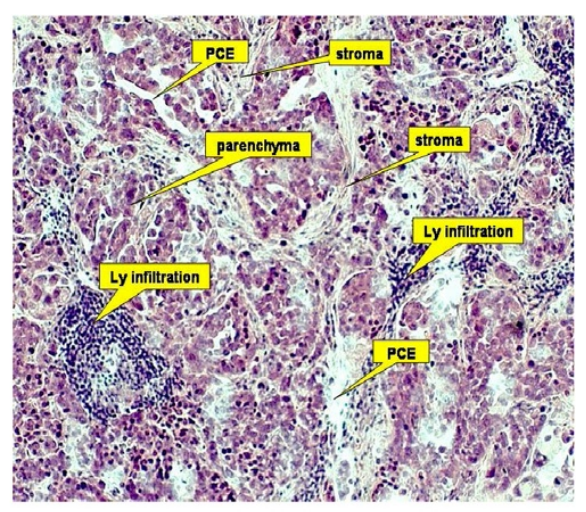

B

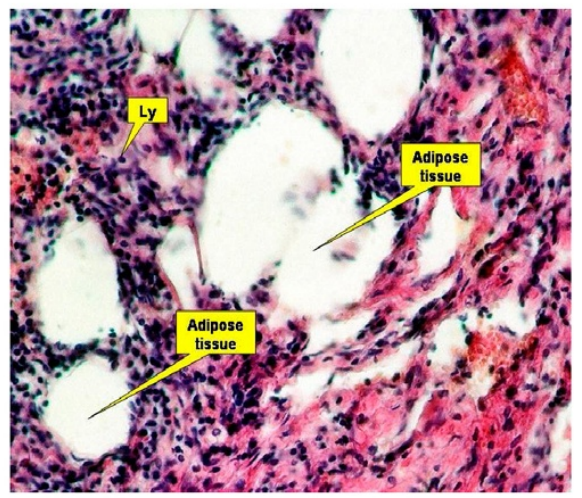

$\mathrm{D}$

Figure 2 Breast cancer morphology (A-D). Ly-lymphocyte (lymhocyte size $\approx 7 \mu \mathrm{m}$ ) is used as a unit; PVE - perivascular edema; PCE - pericellular edema; C - tumor cell enriched in vacuoles is visible on the left side of the microscopic field.

which mimics the intracellular space at the NMR scale. Likely contributors are sclerotic tissue, matured stroma - crosslinked collagen embedded into the carbohydrate matrix, and fat aggregates. Collagen becomes crosslinked when some of the lysyl and hydroxy lysyl sidechains of the amino groups bond to aldehyde groups under the action of a copper-containing oxidase $[49,50])$.

The local extent of stroma may exceed $200 \mu \mathrm{m}$ (Figure 2A), and fat deposition covers several hundred micrometers (Figure 2D). Cancerous tissues are likely to be

Table 3 Self-diffusion coefficients of molecules in the peritumoral breast tissue $(n=3)$

\begin{tabular}{lccccc}
\hline No & $\begin{array}{c}\text { Registered } \\
\text { parameter }\end{array}$ & \multicolumn{4}{c}{ Time of diffusion $\left(\mathbf{t}_{\mathbf{d}}, \mathbf{m s}\right)$} \\
\cline { 3 - 6 } & $\mathbf{1 1}$ & $\mathbf{5 0}$ & $\mathbf{2 0 0}$ & $\mathbf{8 0 0}$ \\
\hline 1 & $\mathrm{ADC}_{\mathrm{m}}\left(10^{-9} \mathrm{~m}^{2} / \mathrm{s}\right)$ & $0,73 \pm 0,55$ & $0,75 \pm 0,05$ & $1,0 \pm 0,1$ & $1,4 \pm 0,1$ \\
2 & $\mathrm{D}_{\mathrm{FDP}}\left(10^{-9} \mathrm{~m}^{2} / \mathrm{s}\right)$, & $1,6 \pm 0,1$ & $1,4 \pm 0,1$ & $1,7 \pm 0,2$ & $1,5 \pm 0,2$ \\
3 & $\mathrm{D}_{\mathrm{SDP}}\left(10^{-11} \mathrm{~m}^{2} / \mathrm{s}\right)$ & $2,2 \pm 0,1$ & $2,0 \pm 0,1$ & $1,8 \pm 0,2$ & $2,2 \pm 0,3$ \\
4 & $P_{1}$ (share) & $0,49 \pm 0,01$ & $0,52 \pm 0,01$ & $0,70 \pm 0.01$ & $0,90 \pm 0.01$ \\
\hline
\end{tabular}

Note: $\mathrm{n}$ - number of the specimens. affected by additional structures. Because the permeability of blood vessels is increased in cancer tissue, fibrin is deposited in the interstitial spaces [51], followed by calcium hydroxylapatite $\left(\mathrm{Ca}_{10}\left(\mathrm{PO}_{4}\right)_{6} \cdot(\mathrm{OH})_{2}\right)$ deposition. The space occupied by these structures may be misinterpreted as intracellular space, leading to overestimates. Vacuoles and vacuole-like structures (Figure $2 \mathrm{C}$ ) are regarded as intracellular spaces [52] and therefore part of the FDP. Although intracellular water has a low diffusion coefficient (ranging from $0.3 \times 10^{-9} \mathrm{~m}^{2} / \mathrm{s}$ to $0.4 \times 10^{-9}$ ), the diffusion coefficient of extracellular water approaches that of pure water $\left((3.0-3.25) \times 10^{-9} \mathrm{~m}^{2} / \mathrm{s}\right.$ at $\left.310 \mathrm{~K}\left(37^{\circ} \mathrm{C}\right)\right)$ [11]. This wide disparity cannot be resolved by diffusion coefficient measurements.

Because free water can rapidly diffuse through intracellular material (at up to two thirds the rate of pure water) [53], the intracellular space may mimic the extracellular space; consequently, the two spaces are indistinguishable by this parameter.

The intracellular space of some cells yields both fast and slow water ADC components. These arise from the 
cytoplasm $\left[\right.$ FDP $=(0.48 \pm 0.14) \times 10^{-9} \mathrm{~m}^{2} / \mathrm{s} ; \mathrm{SDP}=$ $0,034 \times 10^{-9} \mathrm{~m}^{2} / \mathrm{s}$ ] and the nucleus [FDP $=(1.31 \pm$ $\left.0.32) \times 10^{-9} \mathrm{~m}^{2} / \mathrm{s} ; \mathrm{SDP}=(0.057 \pm 0.073) \times 10^{-9} \mathrm{~m}^{2} / \mathrm{s}\right]$ [46].

The intracellular NMR water signal can be monitored in several ways; ct monitoring (by constant diffusion time experiment), ss monitoring (in which a single signal is monitored at large $\mathrm{b}$ value), and $\mathrm{cg}$ monitoring (by constant gradient experiment). In a ct experiment on perfused F98 glioma cells at small b, the signal was induced by extracellular and free diffusing water, and the $\mathrm{ADC}^{\mathrm{ct}}$ was reported as $(3.7 \pm 0.2) \times 10^{-9} \mathrm{~m}^{2} / \mathrm{s}$. At larger $\mathrm{b}$ values the attenuation slope rapidly decreases to $\mathrm{ADC}^{\mathrm{ct}}=(6.0 \pm 0.002) \times 10^{-11} \mathrm{~m}^{2} / \mathrm{s}$. The low $\mathrm{ADC}^{\mathrm{ct}}$ manifests from the restricted diffusion of water inside cells, which suggests that intracellular signals are separable from their extracellular counterparts, and that intracellular signals can be separately detected when b is large [48].

Water diffusion measurements conducted at extremely high $b$ values revealed a multi-exponential decay of the water signal. This indicates the presence of two or three ADCs, depending on the range of the bvalue. Changes in the intracellular signal component have been used to probe the intracellular volume and exchange time under various cellular constraints, such as osmotic stress, apoptotic conditions, immunosuppressive stress, and mercury reagents. In a cg experiment, the mean intracellular residence time of water was determined as approximately $50 \mathrm{~ms}$ [48].

Studies of several cell types have indicated three diffusion characteristics of intracellular water that clearly distinguish it from freely diffusing water (i.e., pure liquid water or dilute aqueous solution). In particular, (1) At typical diffusion times of MR experiments (1-100 ms), the apparent diffusion coefficient (ADC) of intracellular water is less than that of pure water at the same temperature; (2) The ADC of intracellular water decreases with increasing diffusion time; (3) For intracellular water, the MR diffusion signal, denoting the echo amplitude profile of the pulsed field gradient (PFG) acquired during a fixed diffusion time, frequently decays as a non- or monoexponential function of the diffusionweighting b value [48]. These characteristics imply that intracellular water diffusion cannot be characterized by a single ADC. Water diffusion in the cytoplasm of isolated cells, comprising part of the intracellular space, also supports a multiexponential model [46].

In the high $b_{i}$ range $\left(5900-7800 \mathrm{~s} / \mathrm{mm}^{2}\right)$, the signal from fast-moving water is negligible [47]. The extracellular water signal can be suppressed by applying a slice-selective spinecho pulse sequence combined with fast-flowing perfusion media [54], ensuring that the MR signal arises only from intracellular water [53].
Although these experiments certainly separate different water populations, the correlation between these populations and the known physiological compartments is less straightforward.

Depending on the study objectives and experimental conditions, diffusion decay may follow a biexponential, triexponential [55], multiexponential or nonexponential trend. Furthermore, neither intracellular nor extracellular water diffusion can be characterized by a single ADC. The FDP and SDP can be precisely assigned to extracellular $\left(\mathrm{V}_{\mathrm{ex}}\right)$ and intracellular $\left(\mathrm{V}_{\mathrm{in}}\right)$ portions only in packed cells, cultured cells [53], and some isolated tissue structures, such as neurons and muscle strips.

Under the experimental conditions of this study, the A $\left(t_{d}\right)$ with exchange and restricted diffusion is described by a simple sum of two exponents (see Eq. (2) [15] in the background). Recall that we have used the apparent (not the true) values of $\mathrm{P}_{1}, \mathrm{P}_{2}, \mathrm{D}_{\mathrm{FDP}}, \mathrm{D}_{\mathrm{SDP}}$ (Tables 2 and $3)$. The true values of these parameters are their limit values as $2 \tau \rightarrow 0$.

Therefore, the obtained $\mathrm{D}_{\mathrm{FDP}}$ and $\mathrm{D}_{\mathrm{SDP}}$ values (Table 2) compartmentalize the water in breast tissues based on the dynamic properties of water, which may not match the histological location. The latter must be elucidated in $2 \mathrm{D}$ and $3 \mathrm{D}$ diffusion measurements at the microscopic scale of NMR.

\section{Time-dependent diffusion coefficient and its relationship to tissue and medium geometry Short- and long-time diffusion measurements}

The time dependence of diffusion coefficients was initially studied in periodic arrays of parallel non-biological membranes [56]. However, this study overlooked the decrease of the diffusion coefficient at the membrane relative to its bulk value. Instead, it assumed a universal $\sqrt{t}$ behavior dependent only on the surface-to-volume ratio (SV) of the membranes.

The time-dependent diffusion of water and solvents in porous and semipermeable structures has been used to estimate the porous surface and its volume ratio [57], thereby obtaining the average and effective pore size [58] and the deviation of the pore from a spherical geometry [59]. Time-dependent diffusion coefficients in porous media with piecewise-smooth pore-grain interfaces have been evaluated [60] at short times $(<2 \mathrm{~ms})$ and may be simultaneously used to determine $\mathrm{S} / \mathrm{V}$ (where $\mathrm{S}$ is the surface area, $\mathrm{V}$ is the pore volume).

The self-diffusion of polymer (polyethylene glycol and dextran) in cartilage largely depends on the observation time; short-time self-diffusion coefficients (diffusion time $t_{d} \approx 15 \mathrm{~ms}$ ) are influenced by a strong non-specific obstruction effect imposed chiefly by the molecular weight of the polymers and the water content of the cartilage. 
More specifically, the measured self-diffusion coefficients decrease as the molecular weight of the polymers increases, and as the water content of the cartilage decreases. In contrast, the long-time self-diffusion coefficients of polymers in cartilage (diffusion time td $\approx 600 \mathrm{~ms}$ ) reflect the structural properties of the tissue [61].

To obtain the V/S ratio, the short slope of the Padé approximant was fitted by the equation $D(\mathrm{t})=$ $\left[1-(4 / 9 \sqrt{\pi}(S / V)) \sqrt{D_{0} t}\right][60]$ (where $D_{0}$ is the bulk diffusion coefficient of the fluid and $D(\mathrm{t})$ is a timedependent ADC). This result favorably agrees with the size obtained by microscopy [62]. Later, this approach was used to combine PFG with the gradient/radio frequency pulse sequence, yielding several parameters of biological cells; namely, the diffusion coefficient of free intracellular water, the surface-to-volume ratio, the average cell radius, and the variance of cell radius in a collection of cells [53].

To elucidate the restrictions imposed on translational motions of liquid molecules in cells, we investigated the effect of $t_{d}$ on $D_{i}$ in human breast tissues (Table 3).

Two of the diffusion coefficients were independent of diffusion times ranging from $11 \mathrm{~ms}$ to $50 \mathrm{~ms}$. This implies that exchange between the two phases occurs on a much slower timescale $\left(5 \cdot 10^{-2} \mathrm{~s}\right)$ [63].

The absolute values of $\mathrm{D}_{\mathrm{FDP}}$ and $\mathrm{D}_{\mathrm{SDP}}$ were independent of $t_{d}$ throughout the studied range (Table 3). Timeindependence of the measured diffusion constant has sometimes been attributed to unrestricted diffusion [64]; however, it may also be an artefact arising from probing times that are much longer than the time of the restrictive effect [62]. Tissue geometry should be analyzed at

Table 4 The correlation factors ( $r$ ) of the parameters of dynamic characteristics of water molecules with the breast tissues' histological constituents percentage

\begin{tabular}{|c|c|c|c|c|c|c|c|}
\hline Parameter & The group of specimens & Parenchyma & Stroma & Adipose tissue & PCE & PVE & Vessels \\
\hline \multirow[t]{6}{*}{$\mathrm{ADC}_{\mathrm{m}}$} & 1.1 & 1.1.1 & 1.1 .2 & 1.1 .3 & 1.1 .4 & 1.1 .5 & 1.1 .6 \\
\hline & Control & $-0,497$ & $-0,497$ & 0,671 & $-0,598$ & $-0,992$ & 0,895 \\
\hline & 2.1 & 2.1 .1 & 2.1 .2 & 2.1 .3 & 2.1 .4 & 2.1 .5 & 2.1 .6 \\
\hline & Stroma $<50 \%$ & 0,850 & $-0,912$ & $-0,876$ & 0,748 & $-0,837$ & $-0,945$ \\
\hline & 3.1 & 3.1 .1 & 3.1 .2 & 3.1 .3 & 3.1 .4 & 3.1 .5 & 3.1 .6 \\
\hline & Stroma $\geq 50 \%$ & $-0,540$ & $-0,104$ & 0,458 & 0,823 & 0,933 & 0,909 \\
\hline \multirow[t]{6}{*}{$D_{\mathrm{FDP}}$} & 4.1 & 4.1 .1 & 4.1 .2 & 4.1 .3 & 4.1.4 & 4.1 .5 & 4.1 .6 \\
\hline & Control & $-0,130$ & $-0,291$ & 0,252 & $-0,080$ & 0,288 & $-0,186$ \\
\hline & 5.1 & 5.1 .1 & 5.1 .2 & 5.1 .3 & 5.1 .4 & 5.1 .5 & 5.1 .6 \\
\hline & Stroma $<50 \%$ & $-0,149$ & 0,074 & 0,260 & 0,297 & 0,195 & $-0,576$ \\
\hline & 6.1 & 6.1 .1 & 6.1 .2 & 6.1 .3 & 6.1 .4 & 6.1 .5 & 6.1 .6 \\
\hline & Stroma $\geq 50 \%$ & 0,841 & $-0,722$ & 0,500 & 0,295 & $-0,756$ & 0,397 \\
\hline \multirow[t]{6}{*}{$P_{1}$} & 7.1 & 7.1.1 & 7.1 .2 & 7.1 .3 & 7.1.4 & 7.1 .5 & 7.1 .6 \\
\hline & Control & 0,701 & $-0,197$ & $-0,662$ & 0,751 & $-0,114$ & $-0,413$ \\
\hline & 8.1 & 8.1 .1 & 8.1 .2 & 8.1 .3 & 8.1 .4 & 8.1 .5 & 8.1 .6 \\
\hline & Stroma $<50 \%$ & 0,678 & $-0,211$ & $-0,709$ & 0,601 & $-0,202$ & 0,021 \\
\hline & 9.1 & 9.1 .1 & 9.1 .2 & 9.1 .3 & 9.1 .4 & 9.1 .5 & 9.1 .6 \\
\hline & Stroma $\geq 50 \%$ & 0,793 & $-0,895$ & $-0,984$ & 0,800 & 0,872 & $-0,998$ \\
\hline \multirow[t]{6}{*}{$D_{S D P}$} & 10.1 & 10.1.1 & 10.1.2 & 10.1 .3 & 10.1 .4 & 10.1 .5 & 10.1.6 \\
\hline & Control & 0,847 & $-0,130$ & $-0,795$ & 0,763 & $-0,401$ & $-0,304$ \\
\hline & 11.1 & 11.1.1 & 11.1.2 & 11.1 .3 & 11.1.4 & 11.1 .5 & 11.1 .6 \\
\hline & Stroma $<50 \%$ & $-0,243$ & 0,093 & $-0,136$ & 0,239 & $-0,004$ & 0,106 \\
\hline & 12.1 & 12.1.1 & 12.1 .2 & 12.1 .3 & 12.1 .4 & 12.1 .5 & 12.1 .6 \\
\hline & Stroma $\geq 50 \%$ & 0,067 & 0,256 & $-0,516$ & 0,979 & 0,207 & $-0,611$ \\
\hline
\end{tabular}

The significant values of the correlation factors, $\mathrm{p}<0,05$ :

$A D C_{m}: 1.1-1.1 .2 ; p=0,041 ; 2.1-2.1 .2 ; p=0,028 ; 3.1-3.1 .2 ; p=0,045$.

$D_{\text {FDP }}: 5.1$ - 5.1.6; $\mathrm{p}=0,031$.

$D_{S D P}: 10.1-10.1 .1 p=0,033 ; 10.1-10.1 .3 p=0,046 ; 11.1-11.1 .3 p=0,028 ; 12.1-12.1 .3 p=0,016 ; P_{1}: 8.1-8.1 .1 ; p=0,008 ; 8.1-8.1 .3 ; p=0,004 ; 8.1-8.1 .4 p=0,023$. 
Table 5 Dynamic parameters of breast tissues' water molecules are influenced by the histological constituents

\begin{tabular}{|c|c|c|}
\hline Function of dependence & Equation of dependence $(p \leq 0,05)$ & $\mathrm{R}^{2}$ \\
\hline$D_{F D P}=f(P, S t, A T, P C E, ~ V)$ & $D_{\mathrm{FDP}}=4,07^{*}-0,06 \cdot \mathbf{P}^{1}-0,09 \cdot \mathbf{S t}+0,03 \cdot \mathbf{A T}+0,08 \cdot \mathbf{P C E}-0,09 \cdot \mathbf{V}+0,001 \cdot \mathbf{P}^{*}+0,001 \cdot \mathbf{S t}^{2}-0,001 \cdot \mathbf{A T}^{2^{*}}-0,003 \cdot \mathbf{P C E}^{2}+0,005 \cdot \mathbf{V}^{2}$ & 0,92 \\
\hline$D_{S D P}=f(P, S t, A T, P C E, V)$ & $\mathrm{D}_{\mathrm{SDP}}=2,42+0,03 \cdot \mathbf{P}-0,07 \cdot \mathbf{S t}-0,01 \cdot \mathbf{A T}-0,13 \cdot \mathbf{P C E}+0,08 \cdot \mathbf{V}-0,001 \cdot \mathbf{P}^{2}+0,001 \cdot \mathbf{S t}^{2}+0,0002 \cdot \mathbf{A} \mathbf{T}^{2}+0,01 \cdot \mathbf{P C E} \mathbf{E}^{2}-0,005 \cdot \mathbf{V}^{2}$ & 0,81 \\
\hline$P_{1}=f(P, S t, A T, P C E, V)$ & $\mathbf{P}_{1}=1,05+0,02 \cdot \mathbf{P}-0,013 \cdot \mathbf{S t}-0,02 \cdot \mathbf{A T}+0,07 \cdot \mathbf{P C E}-0,02 \cdot \mathbf{V}-0,0004 \cdot \mathbf{P}^{2}+0,00002 \cdot \mathbf{S t}^{2}+0,0002 \cdot \mathbf{A} \mathbf{T}^{2}-0,003 \cdot \mathbf{P C E} \mathbf{E}^{2}+0,004 \cdot \mathbf{V}^{2}$ & 0,93 \\
\hline
\end{tabular}

short diffusion times and gradient pulses (i.e. path lengths shorter than the unit length of the structure) [32]. On larger scales, only the fully restricted (or averaged) diffusion constant is obtained, which equals the asymptotic diffusion coefficient at infinite time.

The minimum observation time is determinable from the minimum length of gradient pulses, the subsequent recovery of the apparatus from eddy currents and magneto-acoustic effects and the signal-to-noise ratio.

Long diffusion times are appropriate for our current breast cancer studies. The increase in the average $\mathrm{ADC}_{\mathrm{m}}$ $\left(t_{d}\right)$ at $t_{d}>50 \mathrm{~ms}$, determined from the initial slope of the diffusion decay (Table 3 ), is explained by the redistribution of the spin populations of both compounds $\left(\mathrm{P}_{1}\right.$ and $P_{2}$ ), which have different relaxation times $T_{1}$ and $T_{2}$ [62]. The $\mathrm{ADC}_{\mathrm{m}}$ is uninformative in our breast tissue specimens, since it cannot separately estimate the translational mobility of each phase.

In a well-connected porous medium, $\mathrm{ADC}(\mathrm{t})$ approaches a non-zero finite value after an extended time. The ADC is reduced by a geometric factor known as the tortuosity, $\alpha$ [65]; specifically, $\operatorname{ADC}(\mathrm{t}) \rightarrow \infty \rightarrow$ $\mathrm{ADC}_{0} / \alpha$. Previous studies [62] have analyzed the longtime behavior in a specific model of packed spherical cells with permeable walls. In this model, the tortuosity factor $(\alpha)$ depends on the permeability. Although $\alpha$ contains geometric information, the same $\alpha$ is obtained in many different geometries [65]. The tortuosity of native breast tissues cannot be evaluated on account because of the tissue complexity. Nevertheless, the ratio (high or low) of the percentage of morphological moieties indirectly reflects the diversity of $\alpha$ within a tissue specimen (Table 1) and also influences the ADC.

\section{Effects of morphological moieties on the diffusion parameters}

Cells aggregate into four major tissue groups: epithelial tissues, supporting and connective tissues (including fatty adipose tissue, cartilage and bone), muscle, and nervous tissue.

Breast contains abundant epithelial tissues and supporting and connective tissues. The latter contain a large amount of extracellular material and ground substance of (mainly) complex carbohydrates and protein polymers. Embryonic fibroblasts differentiate into white and yellow fibers, which form collagen and elastin, respectively. The fibrils of both of these proteins are embedded in the ground substance.

Direct and indirect measurements have proven that NMR parameters are influenced by the biochemical constituents of tissues; that is, their composition and geometrical arrangement (such as morphology and orientation towards a magnetic field) $[23,66,67]$.

The mean residence times of free water molecules range from $10^{-11}$ to $10^{-12} \mathrm{~s}$ [68]. In biological media, the mean residence times are $<(0.1-1) \times 10^{-3} \mathrm{~s}$ in tissues [69], $(12-25) \times 10^{-12} \mathrm{~s}$ in ionic solution [70], $1 \times 10^{-10} \mathrm{~s}$ in lipids [68] and $5 \times 10^{-9} \mathrm{~s}$ to $1 \times 10^{-4} \mathrm{~s}$ in proteins [66].

The $\mathrm{T}_{2}$ relaxation times of water molecules in collagen gels with magnetically oriented and randomly oriented fibers are $0.52 \mathrm{~s}$ and $1.32 \mathrm{~s}$, respectively. The ADCs of water molecules measured with the magnetic pulse

Table 6 Identification of the breast tissues' nature (malignant, nonmalignant) according to theirs morphological constituents percentage or the dynamical properties of water

\begin{tabular}{|c|c|c|}
\hline $\begin{array}{l}\text { Function of } \\
\text { dependence }\end{array}$ & Equation of dependence $(p \leq 0,05)$ & $\mathbf{R}^{2}$ \\
\hline $\begin{array}{l}\text { CanP }^{1}=f(\mathbf{P}, \mathbf{S t}, \mathbf{A T} \\
\mathbf{P C E}, \mathbf{V})\end{array}$ & $\begin{array}{l}\text { CanP }=-2.18+0,099 \cdot \mathbf{P}^{*}+0,031 \cdot \mathbf{S t}-0,004 \cdot \mathbf{A T}-0,02 \cdot \mathbf{P C E}+0,04 \cdot \mathbf{V}-0,001 \cdot \mathbf{P}^{2}-0,0001 \cdot \mathbf{S t}^{2}+0,0004 \cdot \mathbf{A T}^{2}+ \\
0,001 \cdot \mathbf{P C E} \mathbf{E}^{2}+0,0001 \cdot \mathbf{V}^{2}\end{array}$ & 0,66 \\
\hline CanP $=f\left(\mathbf{D}_{\mathrm{FDP}}, \mathbf{D}_{\mathrm{SDP}}\right)$ & CanP $=-3,01+8,02 \cdot \mathbf{D}_{\mathrm{FDP}}+0,84 \cdot \mathbf{D}_{\mathrm{SDP}}-2,36 \cdot \mathbf{D}_{\mathrm{FDP}}^{2}+0,50 \cdot \mathbf{D}_{\mathrm{SDP}}^{2}-2,78 \cdot \mathbf{D}_{\mathrm{FDP}} \cdot \mathbf{D}_{\mathrm{SDP}}$ & 0,69 \\
\hline $\mathrm{CanP}=\mathrm{f}\left(\mathbf{D}_{\mathrm{FDP}}, \mathbf{D}_{\mathrm{SDP}}, \mathbf{P}_{1}\right)$ & $\begin{array}{l}\text { CanP }=2,71+5,69 \cdot \mathbf{D}_{\mathrm{FDP}}-0,59 \cdot \mathbf{D}_{\mathrm{SDP}}-10,21 \cdot \mathbf{P}_{1}-1,41 \cdot \mathbf{D}_{\mathrm{FDP}}^{2}+0,70 \cdot \mathbf{D}_{\mathrm{SDP}}^{2}+1,46 \cdot \mathbf{P}_{1}^{2}-4,19 \cdot \mathbf{D}_{\mathrm{FDP}} \cdot \mathbf{D}_{\mathrm{SDP}}+4,29 . \\
\mathbf{D}_{\mathrm{FDP}} \cdot \mathbf{P}_{1}+2,75 \cdot \mathbf{D}_{\mathrm{SDP}} \cdot \mathbf{P}_{1}\end{array}$ & 0,85 \\
\hline
\end{tabular}

Note: ${ }^{1}$ - cancer probability $(0 \rightarrow 1) ;{ }^{*}$ - the value of certain morphological consituent's percentage, $\mathrm{R}^{2}$ - determination coefficient. 
gradient parallel and perpendicular to the collagen fibers are $2.08 \times 10^{-9} \mathrm{~m}^{2} / \mathrm{s}$ and $1.92 \times 10^{-9} \mathrm{~m}^{2} / \mathrm{s}$, respectively. These differences result from structural changes in the collagen fiber structures induced by the magnetic orientation [66].

Water residence times are also influenced by the secondary structures of sugars (saccharide size, linkage and branching). In particular, they are prolonged, and the translational and rotational dynamics of the water molecules are retarded, in the presence of wide helices and branched sugars. In surrounds of extended helices and smaller oligosaccharides, water dynamics are faster and less hindered. This indicates that the structure and dynamics of carbohydrate surfaces are strongly affected by branching, the type of linkage between monomers, and the anomeric configuration [23].

In nervous tissues, the apparent diffusion coefficient of water is affected by the direction of the axonal fibers [67].

In the present investigation, the self-diffusion coefficients of water in the FDP and SDP restricted or bound with organic and inorganic molecules were evaluated in breast pathology (Tables 2, 4, 5 and 6). Reliable differences were found in the $\mathrm{ADC}_{\mathrm{m}}$ of tissues excised from all cancer patients, in the $\mathrm{D}_{\mathrm{FDP}}$ of all tissue specimens and $\mathrm{T}_{2} \mathrm{~N}_{0} \mathrm{M}_{0}$, and in $\mathrm{P}_{1}$ in $\mathrm{T}_{2} \mathrm{~N}_{1} \mathrm{M}_{0}$ tissues (Table 2). Correlation studies (Table 4) revealed significant relationships between parenchyma and $P_{1}$ value, stroma percentage and $\mathrm{ADC}_{\mathrm{m}}, \mathrm{P}_{1}$ values, and adipose tissue percentage and $\mathrm{D}_{\mathrm{FDP}}$. The $\mathrm{D}_{\mathrm{SDP}}$ and $\mathrm{P}_{1}$ values, pericellular edema percentage and $\mathrm{D}_{\mathrm{SDB}}, \mathrm{P}_{1}$ values, vessels and perivascular edemas percentage are not significantly correlated with either of the diffusion parameters.

Widely variable correlation coefficients, especially those in which the sign depends on the stroma contents, imply a strong influence of the morphological cellular constituents on the tortuosity factor $\alpha$. This interplay will cause variations in $\mathrm{D}_{\mathrm{FDP}}, \mathrm{D}_{\mathrm{SDP}}$ and $\mathrm{P}_{1}$.

Even reliable statistical differences (Tables 1 and 2) [19,21,37] and high correlations (Table 4) [19] do not imply full causality in NMR studies. If a correlation is largely positive or negative, it is incorrect to conclude that a change in one parameter is solely responsible for a change in the correlated parameter [35]. Conversely,

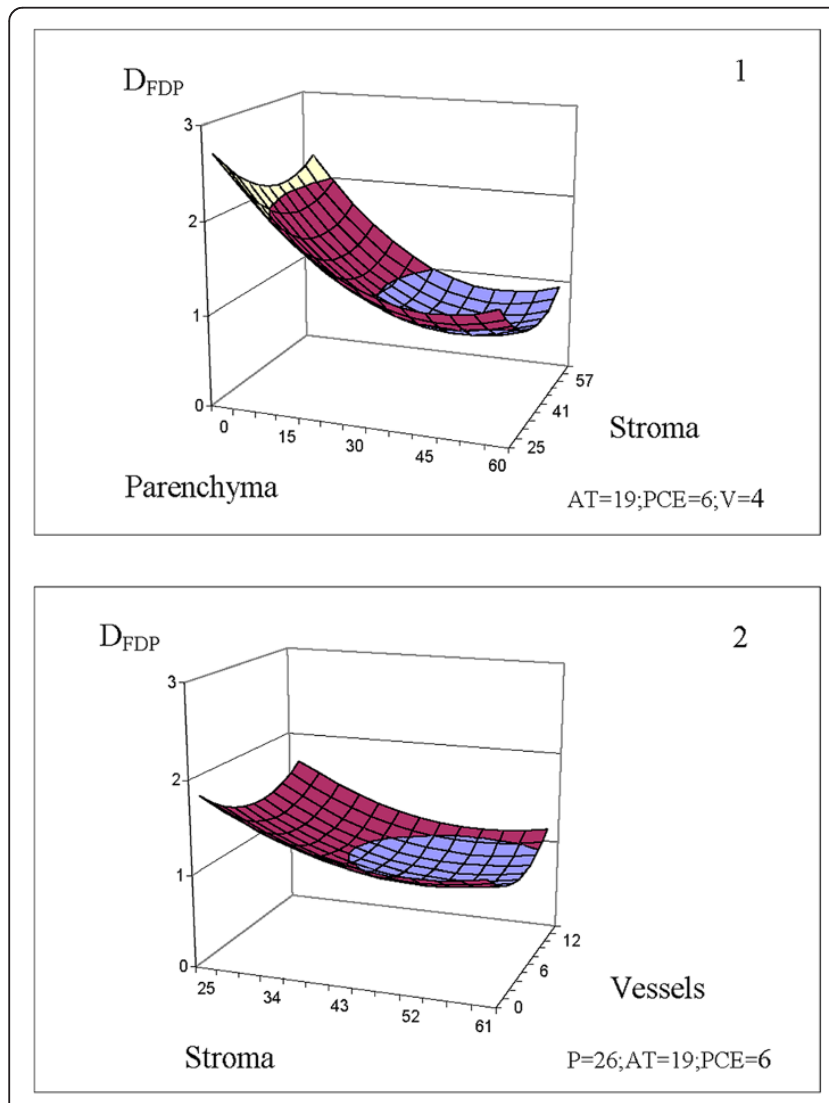

A
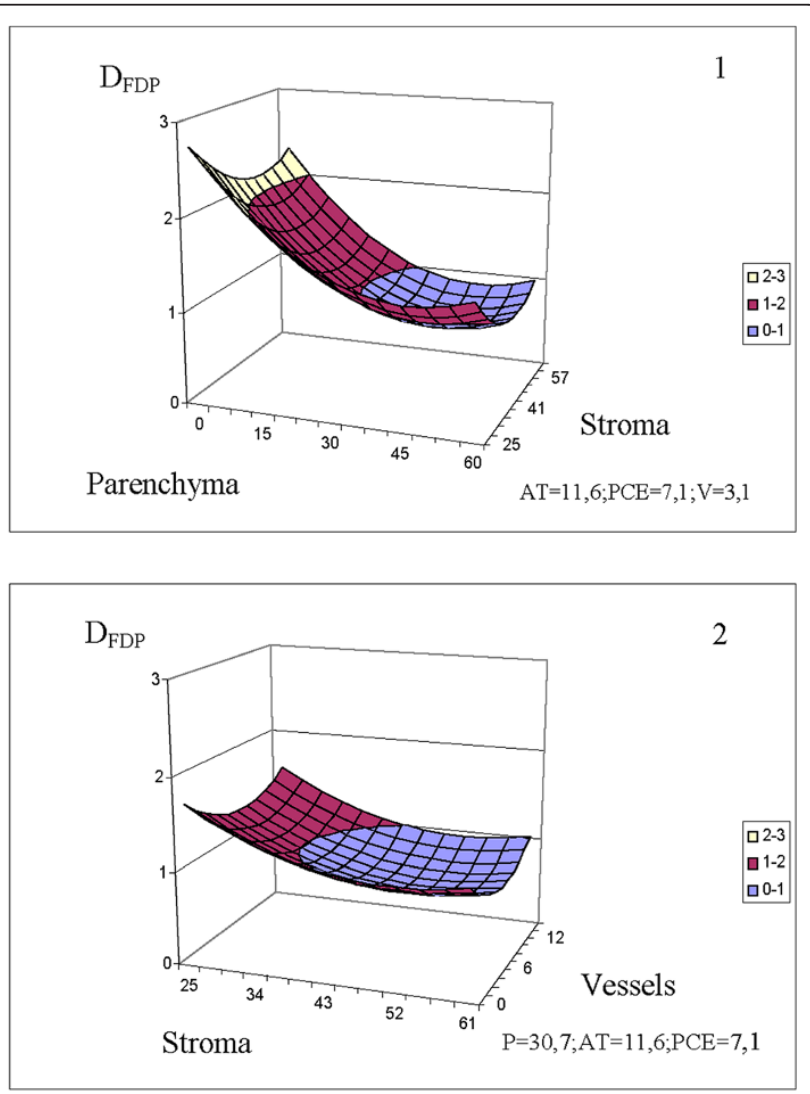

B

Figure $3 D_{\mathrm{FDP}}\left(10^{-9} \mathrm{~m}^{2} / \mathrm{s}\right)$ is stipulated by the morphological constituents' percentage (\%). The values of fixed parameters (AT, PCE, V, P) were picked as: 1. Mean values of the entire group (control + cancer) of samples, index $\mathbf{A}$. 2. Mean values of the malignant specimens only, index $\mathbf{B}$. The scale is shared by $\mathbf{A}$ and $\mathbf{B}$ section. 
practical regression analysis typically adopts models that are more complex than the first-order (straight-line) model; our research was no exception. The modeling design combined 5 (P, St, AT, PCE, V) assessed morphological constituents. PVE's percentage depends on the other morphological constituents. The obtained data were fitted to equations that best described the impact of histological compounds on the values of $\mathrm{D}_{\mathrm{FDP}}, \mathrm{D}_{\mathrm{SDP}}$ and $\mathrm{P}_{1}\left(\mathrm{R}^{2}=0.81-0.93\right.$, Tables 5 and 6).

From the fittings of $\mathrm{D}_{\mathrm{FDP}}$ and $\mathrm{D}_{\mathrm{SDB}}, \mathrm{P}_{1}=\mathrm{f}(\mathrm{P}, \mathrm{St}, \mathrm{AT}$, PCE, V) (Table 5), we can elucidate the contribution of morphological moieties to the FDP and SDP. Specifically, we find that the non-linear coefficients are 10-50 fold less than the linear ones.

Parenchyma reduces the $D_{F D P}$ because this tissue is rich in endoplasmic reticulum (ER), a 50-150-nmwide complex network of membranes. The rough ER is associated with numerous ribosomes (diameter $=21$ $25 \mathrm{~nm}$ ). In addition, cells may contain more than 1000 mitochondria; these complex bodies of width $1 \mu \mathrm{m}$ may occupy almost $24 \%$ of the intracellular area [71]. The $\mathrm{P}_{1}$ (FDP) was positively influenced by $\mathrm{P}$, which may be partially attributed to the FDP-containing regions of the parenchyma cells (Figure 2B, C).

Stroma located in the extracellular space can significantly reduce the fluid properties of surrounding water molecules by virtue of their collagen fibers, which are embedded in the carbohydrate matrix at inter-fiber distances of $2 \mu \mathrm{m}$ (Figure $2 \mathrm{~B}$ ). The ADC of regional water negatively correlates with protein concentration [72].

Adipose tissue is essentially lacking in water molecules (Figure 2D). Nevertheless, unexpectedly given its hydrophobic nature, it exerts a positive and negative influence on the $\mathrm{D}_{\mathrm{FDP}}$ and $\mathrm{D}_{\mathrm{SDP}}$, respectively.

The effect of adipose tissue on $\mathrm{D}_{\mathrm{FDP}}$ can be explained by the liquid low-molecular weight ingredients of fats. Shortchain fatty acids (monoolein, ADC $=0.1 \times 10^{-10} \mathrm{~m}^{2} / \mathrm{s}[73]$ ), glycerol and water molecules (ADC $=10^{-10}$ to $10^{-9} \mathrm{~m}^{2} / \mathrm{s}$ ) [74] can penetrate the fatty acid's tails. They also influence the $\mathrm{D}_{\mathrm{SDP}}$, because the regional water $\mathrm{ADC}$ is inversely correlated with the local lipid concentration [72] (Table 4).

Stroma exerts a negative influence in the equations for $\mathrm{D}_{\mathrm{FDP}}, \mathrm{D}_{\mathrm{SDP}}$ and $\mathrm{P}_{1}$ (Table 5). The percentage of vessels

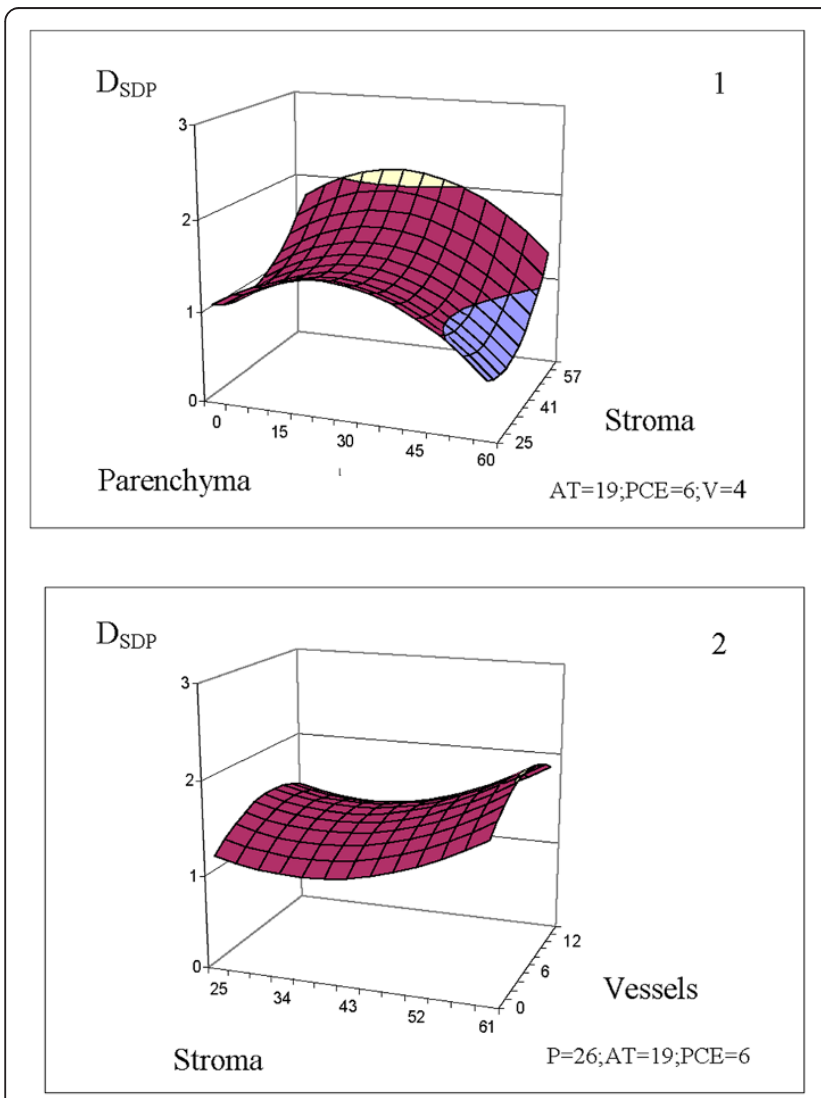

A
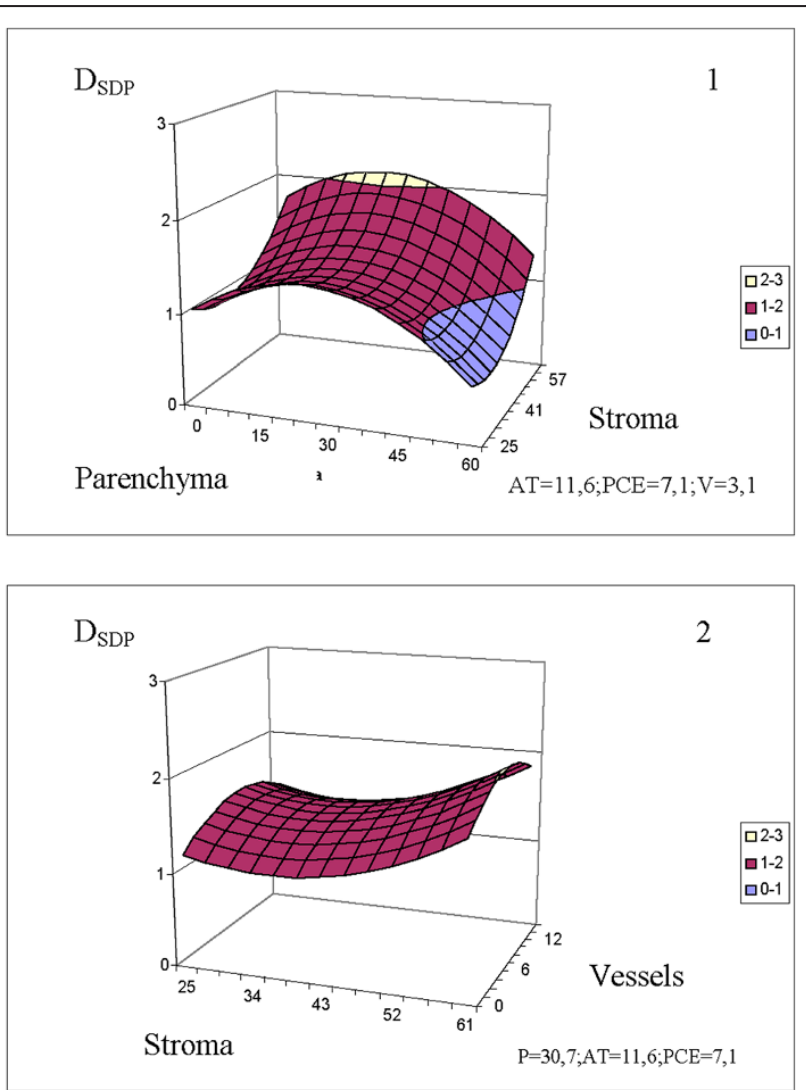

B

Figure $4 D_{S D P}\left(10^{-11} \mathrm{~m}^{2} / \mathrm{s}\right)$ is stipulated by the morphological constituents, percentage (\%). The values of fixed parameters (AT, PCE, $V$, P) were picked as: 1. Mean values of the entire group (control + cancer) of samples, index $\mathbf{A}$. 2. Mean values of the malignant specimens only, index B. The scale is shared by $\mathbf{A}$ and $\mathbf{B}$ sections. 
in the tissue negatively influences the $\mathrm{D}_{\mathrm{FDP}}$ and $\mathrm{P}_{1}$ and positively influences the $\mathrm{D}_{\mathrm{SDP}}$ (Table 5). Lumen areas of vessels are characterized by their hematocrit levels and their volume ratios of insoluble/entire blood compounds ( $\approx 40 \%)$. The negative influence might manifest from the presence of red cells and proteins in the lumen, as well as intramural constituents (elastin) (Figure 2A).

Pericellular edema is a pathological pericellular constituent. This constituent exerts a positive influence on $\mathrm{D}_{\mathrm{FDP}}$ and $\mathrm{P}_{1}$ and a negative influence on $\mathrm{D}_{\mathrm{SDP}}$.

We find that P, St and PCE depend on the stroma contents of tissues and change sign in the equations describing $\mathrm{D}_{\mathrm{FDP}}, \mathrm{D}_{\mathrm{SDP}}, \mathrm{P}_{1}$. These results imply a dual (intracellular and extracellular) origin of both FDP and SDP. We conclude that the dynamic parameters of water in tissues are significantly influenced by the morphological moieties.

\section{Opportunity for distinguishing tissue malignancy from NMR parameters of water dynamics}

The relaxation time of tissues and the dynamic parameters of their contained water depend more heavily on the water content and the extent of necrosis and fibrosis, than on histological structure [75]. Later, tumor cellularity was found to be negatively correlated with mean ADC [19].

Elevated water-fat ratios have been identified in the MR spectra of malignant tissues in vivo, and compared with both the normal breast tissue of healthy controls and the contralateral unaffected breast tissue of the patients. When the primary tumor size is reduced by chemotherapy, the water-fat ratio decreases relative to its pre-therapy level [76].

Algorithms that discriminate between benign and malignant breast lesions are divisible into two classes; physiologically model-based and model-free.

Model-based methods focus on the physiological meaning of constructed dynamic-contrast-enhanced (DCE) time curves [77]. These models require additional measurements, such as blood AIF (arterial input function) and pre-contrast $\mathrm{T}_{1}$ relaxation rate.

Model-free algorithms attempt to overcome the limitations [77] inherent in diagnostic evaluation of breast cancer. Factor analysis of medical image sequences

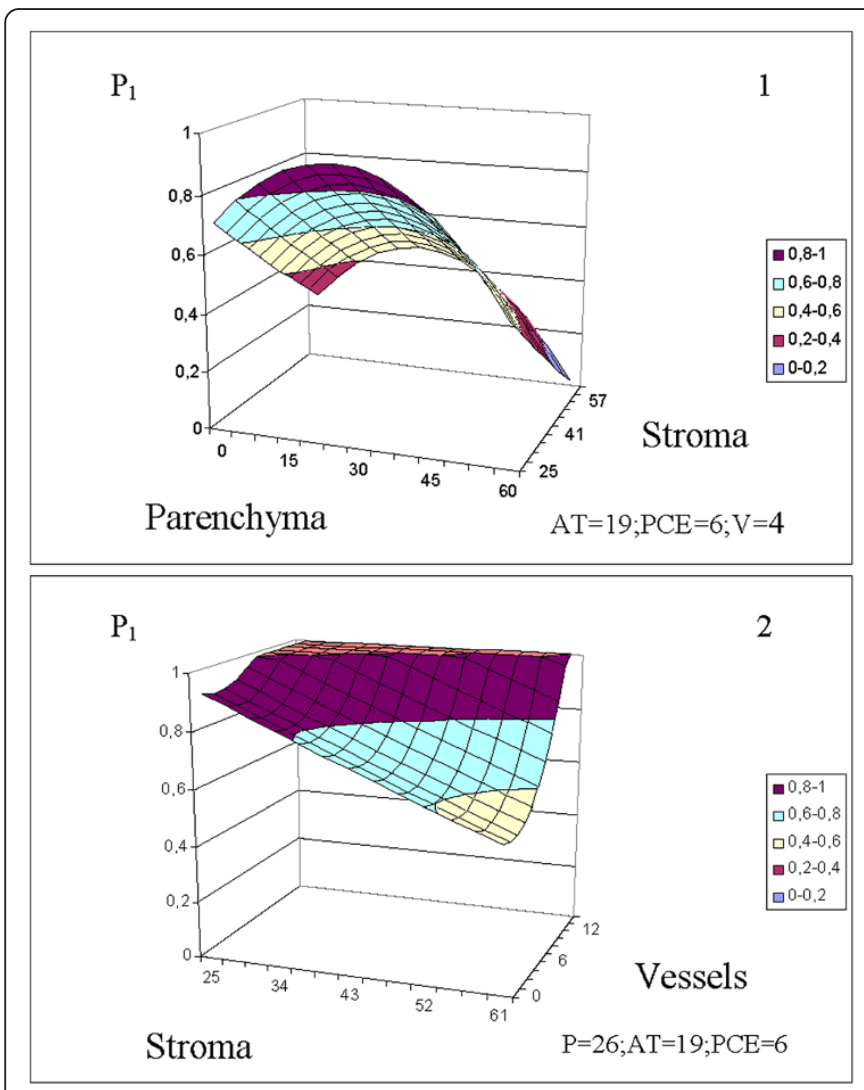

A
$\mathrm{P}_{1}$

Parenchyma

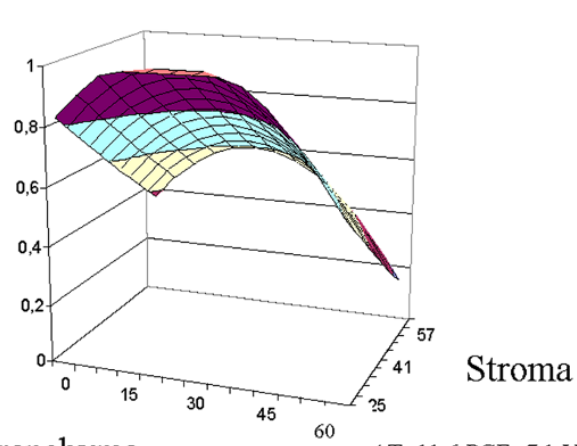

1

$0,6-0,8$

$\square, 4-0,6$

0,2-0,4

$\square 0-0,2$

troma

$\mathrm{TT}=11,6 ; \mathrm{PCE}=7,1 ; \mathrm{V}=3,1$

$\mathrm{P}_{1}$

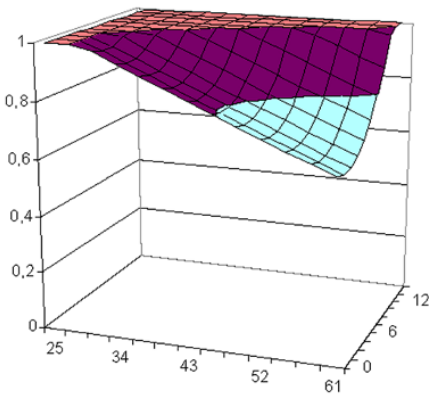

2

Stroma
$\mathrm{P}=30,7 ; \mathrm{AT}=11,6 ; \mathrm{PCE}=7$

Figure $\mathbf{5} \mathbf{P}_{\mathbf{1}}$ is stipulated by the morphology constituents, percentage (\%). The values of fixed parameters (AT, PCE, V, P) were picked as: 1. Mean values of the entire group (control + cancer) of samples, index $\mathbf{A}$. 2. Mean values of the malignant specimens only, index $\mathbf{B}$. 
(FAMIS), principal component analysis (PCA) and independent component analysis reveal the physiological dynamics of the target tissue. Artificial neural network (ANN) is a commonly used clustering algorithm that permits dynamic and textural analysis, and the "fuzzy-c" means (FCM) algorithm incorporates logistic regression texture and age.

In the present study, we verified cancer tissues from their morphology and diffusional parameters (Tables 5 and 6) using non-linear regression analysis [35]. In the linear regression analysis $\mathrm{y}=\mathrm{b}_{0}+\sum_{j=1}^{k} b_{j} x_{j}$ the determination coefficient was very low $\left(\mathrm{R}^{2}=0.3-0.4\right)$.

In all cases, the most relevant factors in cancer diagnosis are the morphological compounds (P, St, AT, V,
PCE, and PVE). Inserting these parameters into the equation for cancer probability, namely, $(\mathrm{Can} P)=\mathrm{f}(\mathrm{P}$, St, AT, PCE, V), cancer was correctly diagnosed in $66 \%$ $\left(R^{2}=0.66\right)$ of cases.

In this case, since the non-linear coefficients are 10400 fold less than the linear ones $(\mathrm{CanP}=\mathrm{f}(\mathrm{P}, \mathrm{St} . .$.$) ; see$ Table 5), and the values of $\left(\mathrm{D}_{\mathrm{FDP}}\right)^{2},\left(\mathrm{D}_{\mathrm{SDP}}\right)^{2}, \mathrm{D}_{\mathrm{FDP}} \cdot \mathrm{D}_{\mathrm{SDP}}$, $\mathrm{D}_{\mathrm{FDP}} \cdot \mathrm{P}_{1}, \mathrm{D}_{\mathrm{SDP}} \cdot \mathrm{P}_{1}$ are much less than $1.0-$ (respectively, $\left(10^{-9}\right)^{2} \mathrm{~m}^{2} / \mathrm{s},\left(10^{-11}\right)^{2} \mathrm{~m}^{2} / \mathrm{s},\left(10^{-9}\right) \mathrm{m}^{2} / \mathrm{s},\left(10^{-11}\right)$ $\left.\left.\mathrm{m}^{2} / \mathrm{s}\right), \mathrm{P}_{1}<1,0\right)$, we can approximate the cancer probabilities by linear functions of $\mathrm{D}_{\mathrm{FDP}}, \mathrm{D}_{\mathrm{SDP}}$ and $\mathrm{P}_{1}$; that is, $\mathrm{CanP}=\mathrm{f}\left[\mathrm{D}_{\mathrm{FDP}}, \mathrm{D}_{\mathrm{SDP}}\right)$ and $\left.\mathrm{CanP}=\mathrm{f}\left(\mathrm{D}_{\mathrm{FDP}}, \mathrm{D}_{\mathrm{SDP}}, \mathrm{P}_{1}\right)\right]$ (Table 6).

Cancer probability is positively influenced by the P, St, and $\mathrm{V}$ constituents, the main targets in histological cancer revelation. The AT and PCE lack any morphological

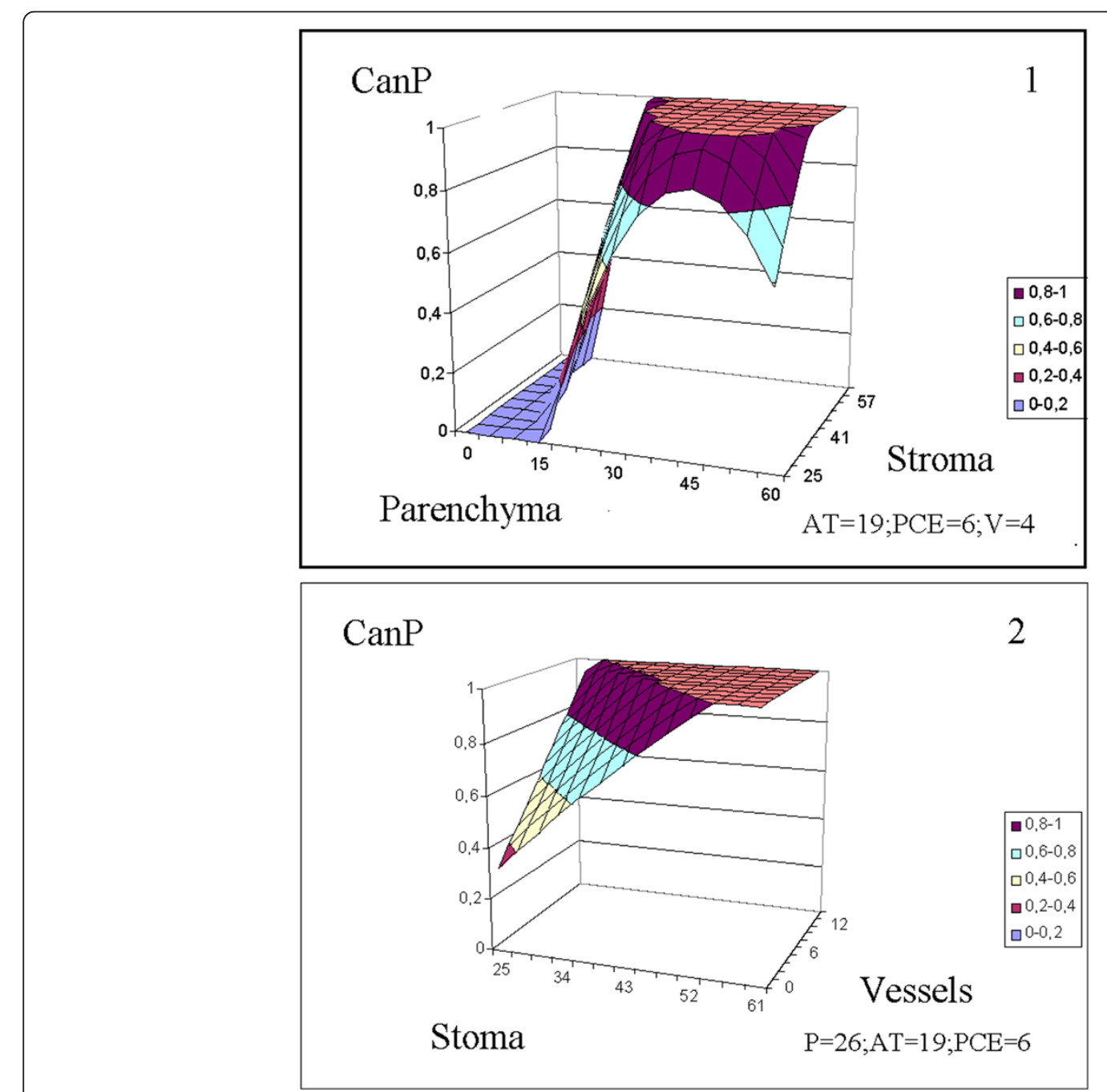

Figure 6 Cancer tissues identification according to the morphological constituents' percentage (\%). The values of fixed parameters (AT, $P C E, V, P)$ were picked as mean values of the entire group (control + cancer) of specimens. 

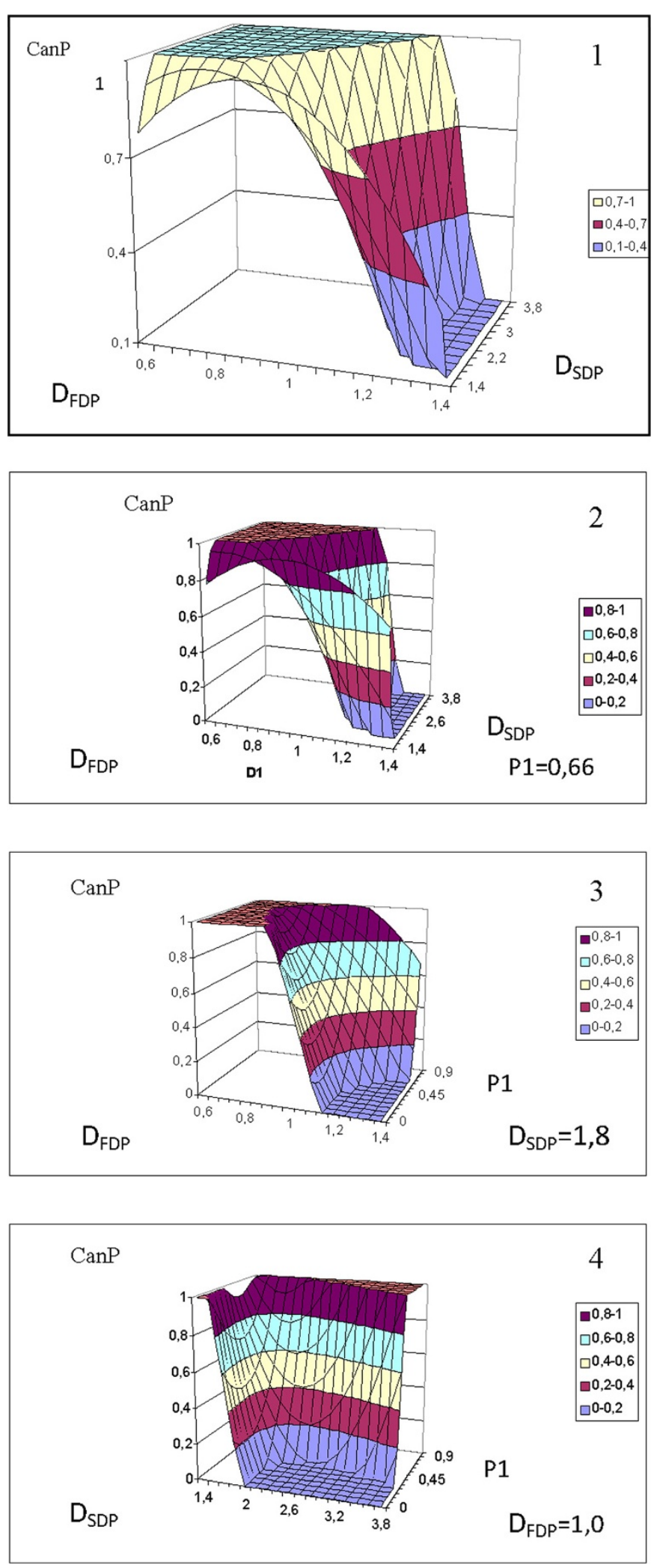

Figure 7 Cancer tissues identification according to the values of $D_{\mathrm{FDP}} 10^{-9} \mathrm{~m}^{2} / \mathrm{s}, D_{\mathrm{SDP}} 10^{-11} \mathrm{~m}^{2} / \mathrm{s}(1), D_{\mathrm{FDP}} 10^{-9} \mathrm{~m}^{2} / \mathrm{s}, D_{\mathrm{SDP}} 10^{-11} \mathrm{~m}^{2} / \mathrm{s}, \mathrm{P}_{1}$ (2-4). The values of fixed parameters $\left(D_{F D P}, D_{S D P}, P_{1}\right)$ were picked as mean values of the entire group (control + cancer) of specimens. 
specificity for classification purposes in cancerous breast tissues, and both parameters exert a negative influence on cancer probability. More observations are required for a definite assessment of these phenomena.

The cancer probability equations defined above are useful because they directly relate the tissue constituents to the dynamical water parameters $\left(\mathrm{D}_{\mathrm{FDP}}, \mathrm{D}_{\mathrm{SDP}}\right.$ and $\left.\mathrm{P}_{1}\right)$, which are evaluable in in vivo studies. The equation $\mathrm{CanP}=\mathrm{f}\left(\mathrm{D}_{\mathrm{FDP}}, \mathrm{D}_{\mathrm{SDP}}\right)$ demonstrates equivalent information efficacy $\left(R^{2}=0.69\right)$ to $\operatorname{CanP}=f(P, S T, A T)$. By incorporating $\mathrm{P}_{1}, \mathrm{R}^{2}$ is significantly increased to 0.85 (Table 6).

The predictions of the equations are visually clarified by the 3D plots in Figures 3, 4, 5, 6 and 7. The fixed parameters (AT, PCE, $\mathrm{P}, \mathrm{V}$ ) input to the appropriate equations (Table 5, Figures 3, 4 and 5) were selected as (1) the mean values of the entire sample group (control + cancer; Figures 3, 4 and 5, panels A) and (2) the mean values of the malignant samples only (Figures 3, 4 and 5, panels B).

P, St and V were selected as the parameters for which $\mathrm{D}_{\mathrm{FDP}}, \mathrm{D}_{\mathrm{SDP}}$ and $\mathrm{P}_{1}$ depend on (1) the proportion of parenchyma, which reflects the cellularity of the tissue; (2) the percentage of stroma (collagen), which influences the ADC [66] (Table 4, $\mathrm{ADC}_{\mathrm{m}}$ ), and whose biosynthesis is altered in cancer tissue [78], and (3) micro-vessel counts, which are higher in malignant than in benign pathologies $[79,80]$.

The influences of the remaining constituents, PVE, PCE [81] and especially AT[82], are of immense interest, but a detailed analysis of $\mathrm{D}_{\mathrm{FDB}} \mathrm{D}_{\mathrm{SDP}}$ and $\mathrm{P}_{1}$ as functions of the cell histology is beyond the scope of this paper. Nevertheless, we can highlight two features: 1 . We can observe the sensitivity of the equations (Table 6) $D_{\mathrm{FDP}}=\mathrm{f}$ $(\mathrm{P}, \mathrm{St}, \mathrm{AT}, \mathrm{PCE}, \mathrm{V}), \mathrm{D}_{\mathrm{SDP}}=\mathrm{f}(\mathrm{P}, \mathrm{St}, \mathrm{AT}, \mathrm{PCE}, \mathrm{V}) \mathrm{P}_{1}=\mathrm{f}(\mathrm{P}$, St, AT, PCE, V) to fluctuations in the morphological constituents of the specimen tissues. Sensitivity analyses can be conducted over a wide range of parenchyma percentages $(0-60 \%)$, stroma percentages $(25-61 \%)$, and vessel percentages $(0-12 \%)$, considering both the entire group of specimens [Figures $3 \mathrm{~A}(1-2), 4 \mathrm{~A}(1-2), 5 \mathrm{~A}(1-2)$ ] and malignant specimens only [Figures $3 \mathrm{~B}(1-2), 4 \mathrm{~B}(1-2)$, $5 \mathrm{~B}(1-2)]$.

2. Because the plots of $\operatorname{CanP}(\mathrm{St}, \mathrm{P})$ and $\mathrm{CanP}(\mathrm{St}, \mathrm{V})$ in Figure 6, and those of CanP $\left(\mathrm{D}_{\mathrm{FDP}}, \mathrm{D}_{\mathrm{SDP}}\right)$ and CanP $\left(D_{\mathrm{FDP}}, \mathrm{D}_{\mathrm{SDP}}, \mathrm{P}_{1}\right)$ in Figure 7 develop flat regions at 0 and 1 , we can identify tissue specimens that are unambiguously malignant (1) or certainly nonmalignant $(\mathbf{0})$.

The obtained equations avoid the need for procedures that are essential in DCE-MRI [77]; namely, intravenous contrast injection, division of patient data into training and test datasets, high computational cost in image processing, and accentuation of the breast cancer region by an expert.

\section{Conclusion}

Biological tissue comprises $65-75 \%$ water. Because the concentration of pure water is $55 \mathrm{Mol}\left({ }^{1} \mathrm{H}\right.$ concentration $=110 \mathrm{Mol}$ ), the NMR signal is detectable even in tiny voxels, where the tissue extends by $<0.5 \mathrm{~mm}$ each side.

The number of water molecules exhibiting free and hindered diffusion may differ among the various compartments of a tissue. The intrinsic ADCs may also vary among these compartments. Furthermore, a certain proportion of the water molecules in each compartment may be restricted by impermeable and semipermeable barriers, depending on the tissue morphology (biochemical composition, geometry and size of the confining compartment), the diffusion coefficients, and the time over which the diffusion process is probed. The ADC reflects the compartmentalization of water more by its dynamic properties than by its histological location.

Histological components of the tissue are related to the diffusion biexponential model parameters. Therefore, they can be used to determine the relative probability of cancer in a given specimen with some certainty.

\section{Abbreviations}

n: Number of samples; FDP: Fast diffusion phase of water; SDP: Slow diffusion phase of water; ADC: Apparent diffusion coefficient; $A D C_{m}$ : Averaged apparent diffusion coefficient; $D_{F D P}, D_{S D P}$ : Diffusion coefficients and $P_{1}, P_{2}$ - spin populations of "FDP" and "SDP" water; P: Parenchyma; St: Stroma; AT: Adipose tissue; V: Vessels; PCE: Pericellular edema; PVE: Perivascular edema; PFG: Pulsed field gradient;

DW-MRI: Diffusion weighted MRI.

\section{Competing interests}

The authors declare that they have no competing interests.

\section{Authors' contributions}

All the authors have made substantial contributions to manuscript: BRF- the conception and design of study analysis and interpretation of data; GRAconceived of the study, participated in its design, coordination and helped to draft the manuscript, SKK - carried out the histology assays; SSZ - substantial analysis; MFR- participated in the design of the study and performed the statistical analysis; STA performed NMR measurements. All authors read and approved the final manuscript.

\section{Authors' information}

RF, Full professor of Biochemistry, MD, PhD, Dr. Sci. Med. ; RA, MD; KK, MD; $\mathrm{SZ}, \mathrm{MD}, \mathrm{PhD} ; \mathrm{FR}$, biologist; TA, PhD.

\section{Acknowledgments}

Thanks to the patients who contributed samples to this research. We are grateful to GI Vasiliev (Kazan Federal University) for the technical support during NMR measurements, DE Tzyplakov (Kazan State Medical University) for the cooperation in the morphology studies and for MM Drogynytsky (Kazan Federal University) for useful discussion.

\section{Author details}

${ }^{1}$ Department of Biochemistry, Kazan State Medical University, Butlerova St., 49, Kazan, Tatarstan, Russia. ${ }^{2}$ Kazan Oncological Dispensary, Baturina St., 7. Kazan, Tatarstan, Russia. ${ }^{3}$ Kazan Institute of Biochemistry and Biophysics of Russian Academy of Science, Kazan, Tatarstan, Russia.

Received: 14 February 2013 Accepted: 18 November 2014 Published: 8 December 2014 


\section{References}

1. Mattea C, Qvist J, Halle B: Dynamics at the protein-water interface from ${ }^{17} \mathrm{O}$ spin relaxation in deeply supercooled solutions. Biophys $J$ 2008, 95:2951-2963.

2. Meiboom S: Nuclear magnetic resonance study of the proton transfer in water. J Chem Physiol 1961, 34:375-388.

3. Sehy JV, Ackerman JJ, Neil JJ: Apparent diffusion of water, ions and small molecules in the Xenopus oocyte is consistent with Brownian displacement. Magn Reson Med 2002, 48:42-51.

4. Stejskal EO, Tanner JE: Spin diffusion measurements:spin echoes in the presence of a time-dependent field gradient. J Chem Phys 1965, 42:288-292.

5. Callaghan PT: Pulsed field gradient nuclear magnetic resonance as probe of liquid state molecular organization. Aust J Phys 1984, 37:359-387.

6. Price WS: Pulsed field gradient NMR as a tool for studying translational diffusion. Part I. Basic theory. Concepts Magn Reson 1997, 9:299-336.

7. Kärger J: Zun Massbarkeit von Diffusionkoeffizienten in Zweiphase System mit Hilfe der Methode der Gepulsten Feldgradienten. Ann Phys 1969, 24:1-7 (DDR).

8. Lee $\mathrm{JH}$, Springer CS: Effects of equilibrium exchange on diffusionweighted NMR signals: the diffusigraphic "shutter-speed". Magn Reson Med 2003, 49:450-458.

9. Price WS, Barzykin AV, Hayamizu K, Tachiya M: A model for diffusive transport through a spherical interface probed by pulsed-field gradient NMR. Biophys J 1998, 74:2259-2271.

10. Roth Y, Ocherashvilli A, Daniels D, Ruiz-Cabello J, Maier SE, Orenstein A, Mardor Y: Quantification of water compartmentation in cell suspensions by diffusion-weighted and $\mathrm{T}_{2}$-weighted MRI. Magn Reson Imaging 2008, 26:88-102.

11. Novikov EG, van Dusschoten D, Van As H: Modeling of self-diffusion and relaxation time NMR in multi-compartment systems. J Magn Reson 1998, 135:522-528.

12. Sukstanskii AL, Yablonskiy DA, Ackerman JJ: Effects of permeable boundaries on the diffusion-attenuated MR signal: insights from a onedimensional model. J Magn Reson 2004, 170:56-66.

13. Yablonskiy DA, Bretthorst GL, Ackerman JJ: Statistical model for diffusion attenuated MR signal. Magn Reson Med 2003, 50:664-669.

14. van Gelderen P, de Vleeschouwer MH, DesPres D, Pekar J, Van Zijl PC, Moonen CT: Water diffusion and acute stroke. Magn Reson Med 1994 31:154-163

15. Niendorf T, Dijkhuizen RM, Norris DG, van Lookeren CM, Nicolay K: Biexponential diffusion attenuation in various states of brain tissue: implications for diffusion-weighted imaging. Magn Reson Med 1996, 36:847-857.

16. Mulkern RV, Gudbjartsson H, Westin CF, Zengingonul HP, Gartner W, Guttmann CR, Robertson RL, Kyriakos W, Schwartz R, Holtzman D, Jolesz FA, Maier SE: Multi-component apparent diffusion coefficients in human brain. NMR Biomed 1999, 12:51-62.

17. Clark CA, Le Bihan D: Water diffusion compartmentation and anisotropy at high $b$ values in the human brain. Magn Reson Med 2000, 44:852-859.

18. Tamura T, Usui S, Murakami S, Arihiro K, Akiyama Y, Naito K, Akiyama M: Biexponential Signal Attenuation Analysis of Diffusion-weighted Imaging of Breast. Magn Reson Med Sci 2010, 9:195-207.

19. Guo Y, Cai YQ, Cai ZL, Gao YG, An NY, Ma L, Mahankali S, Gao JH: Differentiation of clinically benign and malignant breast lesions using diffusion-weighted imaging. J Magn Reson Imaging 2002, 16:172-178.

20. Boes JL, Hoff BA, Hylton N, Pickles MD, Turnbull LW, Schott AF, Rehemtulla A, Chamberlain R, Lemasson B, Chenevert TL, Galb NCJ, Meyer CR: Image registration for quantitative parametric response mapping of cancer treatment response. Trans/ Oncol 2014, 7:101-110.

21. Marini C, lacconi C, Giannelli M, Cilotti A, Moretti M, Bartolozzi C: Quantitative diffusion-weighted MR imaging in the differential diagnosis of breast lesion. Eur Radiol 2007, 17:2646-2655.

22. Tan SL, Rahmat K, Rozalli Fl, Mohd-Shah MN, Aziz YF, Yip CH, Vijayananthan A, Ng KH: Differentiation between benign and malignant breast lesions using quantitative diffusion-weighted sequence on $3 \mathrm{~T}$ MRI. Clin Radiol 2014, 69:63-67.

23. Ramadugu SK, Chung YH, Xia J, Margulis CJ: When sugars get wet. A comprehensive study of the behavior of water on the surface of oligosaccharides. J Phys Chem B 2009, 113:11003-11015.

24. Partridge SC, Murthy RS, Ziadloo A, White SW, Allison KH, Lehman CD: Diffusion tensor magnetic resonance imaging of the normal breast. J Magn Reson Imaging 2010, 28:320-328.
25. Partridge SC, Ziadloo A, Murthy RS, White SW, Peacock S, Eby PR, DeMartini WB, Lehman CD: Diffusion tensor MRI: preliminary anisotropy measures and mapping of breast tumors. J Magn Reson Imaging 2010, 31:339-347

26. Kuroki Y, Nasu K, Kuroki S, Murakami K, Hayashi T, Sekiguchi R, Nawano S: Diffusion - weighted imaging of breast cancer with the sensitivity encoding technique: analysis of the apparent diffusion coefficient value. Magn Reson Med Sci 2004, 3:79-85.

27. Boger W, Gruber S, Pinker K, Grabner G, Stadlbauer A, Weber M, Moser E, Helbich TH, Trattnig S: Diffusion-weighted MR for differentiation of breast lesions at 3.0 T: how does selection of diffusion protocols affect diagnosis? Radiol 2009, 253:341-351.

28. Sun Y, Mulkern RV, Schmidt K, Doshi S, Albert MS, Schmidt NO, Ziu M, Black $P$, Carrol R, Kieran MW: Quantification of water diffusion and relaxation times of human U87 tumors in a mouse model. NMR Biomed 2004, 17:399-404.

29. Tsushima Y, Takahashi-Taketomi A, Endo K: Magnetic resonance (MR) differential diagnosis of breast tumors using apparent diffusion coefficients (ADC) on 1.5-T. J Magn Reson Imaging 2009, 30:249-255.

30. Peters NH, Vincken KL, van den Bosch MA, Luijten PR, Mali WP, Bartels LW: Quantitative diffusion weighted imaging for differentiation of benign and malignant breast lesions: the influence of the choice of b-values. J Magn Reson Imaging 2010, 31:1100-1105.

31. Baron P, Dorrius MD, Kappert P, Oudkerk M, Sijens PE: Diffusion-weighted imaging of normal fibroglandular breast tissue: influence of microperfusion and fat suppression technique on the apparent diffusion coefficient. NMR Biomed 2010, 23:399-405.

32. Tanner JE, Stejskal EO: Restricted self-diffusion of protons in colloidal systems by the pulsed-gradient, spin-echo method. J Chem Phys 1968 49:1768-1777.

33. Bell EL, Garsia R: Fitting Multi-Component Exponential Decay Curves by Digital Computer. Brooks AFB, TX: USAF School of Aerospace Medicine AFSC; 1965:45.

34. Stephanov SB: Morphometrical scale of random step as a tool of accelerated measurement of elemental morphogenesis. Cytologiya (RU) 1974, 16:785-787.

35. Mendenhall W, Sincich TL: A Second Course in Statistics: Regression Analysis. 5th edition. Upper Saddle River, NJ: Prentice Hall; 1996:899.

36. Gubanov RA, Safin KR, Safina SZ, Baikeev RF: Informative evaluation of tumor markers in breast cancer. Creative surgery and oncology 2011, 4:59-66.

37. Yoshikawa Ml, Ohsumi S, Sugata S, Kataoka M, Takashima S, Kikuchi K, Mochizuki T: Comparison of breast cancer detection by diffusionweighted magnetic resonance imaging and mammography. Radiat Med 2007, 25:218-223.

38. Wang $L$, Wang $D$, Fei $X$, Ruan $M, C$ Chai $W$, Xu L, Li X: A rim-enhanced mass with central cystic changes on MR imaging: how to distinguish breast cancer from inflammatory breast diseases? Plos ONE 2014, 5:e90355.

39. McLaughlin RL, Newitt DC, Wilmes LJ, Jones EF, Wisner DJ, Kornak J, Proctor E, Joe BN, Hylton NM: High resolution in vivo characterization of apparent diffusion coefficient at the tumor-stromal boundary of breast carcinomas: a pilot study to assess treatment response using proximitydependent diffusion weighted imaging. J Magn Reson Imaging 2014, 39:1308-1313.

40. Mcdonald ES, Schopp JG, Peacock S, DeMartini WD, Raybar H, Lehman CD Partridge SC: Duffusion-weighted MRI: association between characteristics and apparent diffusion coefficients of normal breast fibroglandular tissue at 3T. Am J Roentgenol 2014, 202:W496-W502.

41. Cai H, Peng Y, Ou C, Chen M, Li L: Diagnosis of breast masses from dynamic contrast-enhanced and diffusion-weighted MR: a machine learning approach. PLOS One 2014, 9:e87387.

42. Basser PJ, Mattiello J, LeBihan D: Estimation of the effective self-diffusion tensor from the NMR spin echo. J Magn Reson B 1994, 103:247-254.

43. Iwasa H, Kubota K, Hamada N, Nogami M, Nishioka A: Early prediction of response to neoadjuvant chemotherapy in patients with breast cancer using diffusion weighted imaging and gray-scale ultrasonography. Oncol Rep 2014, 31:1555-1560.

44. Moschetta M, Telegrafo M, Rella L, Capolongo A, Stable lanora AA, Angelelli G: MR evaluation of breast lesions obtained by diffusion-weighted imaging with background body signal suppression (DWIBS) and correlations with histological findings. Magn Reson Imaging 2014, 32:605-609. 
45. Woodhams R, Kakita S, Hata H, Iwabuchi K, Umeoka S, Mountford CE, Hatabu $H$ : Diffusion-weighted imaging of mucinous carcinoma of the breast: evaluation of apparent diffusion coefficient and signal intensity in correlation with histologic findings. Am J Roentgeno/ 2009, 193:260-266.

46. Sehy JV, Ackerman JJ, Neil JJ: Evidence that both fast and slow water ADC components arise from intracellular space. Magn Reson Med 2002, 48:765-770

47. Pfeuffer J, Bröer S, Bröer A, Lechte M, Flögel U, Leibfritz D: Expression of aquaporins in Xenopus laevis oocytes and glial cells as detected by diffusion-weighted ${ }^{1} \mathrm{H}$ NMR spectroscopy and photometric swelling assay. Biochim Biophys Acta 1998, 1448:27-36.

48. Flögel U, Pfeuffer J, Leibfritz D: Alterations in Glial Cell Metabolism during Oxygen Deprivation studied by Multinuclear NMR Spectroscopy. Vancouver: Proc., SMRM, 5th Scientific Meeting; 1997:1391.

49. Eyre DR: Collagen: molecular diversity in the body's protein scaffold. Science 1980, 207:1315-1322.

50. Tanaka S, Avigad G, Eikenberry EF, Brodsky B: Isolation and partial characterization of collagen chains dimerized by sugar-derived cross-links. J Biol Chem 1998, 263:17650-17657.

51. Baikeev RF: Tissue Destruction and Blood Coagulation. Kazan: Remark; 1994:216.

52. Metzler DE: Biochemistry. The Chemical Reactions of Living Cells. 2nd edition. San Diego, CA: Harcourt/Academic Press; 2001:1973.

53. Zhao L, Sukstanskii AL, Kroenke CD, Song J, Piwnica-Worms D, Ackerman JJ, Neil JJ: Intracellular water specific MR of microbead-adherent cells: HeLa cell intracellular water diffusion. Magn Reson Med 2008, 59:79-84.

54. Zhao L, Kroenke CD, Song J, Piwnica-Worms D, Ackerman JJ, Neil JJ: Intracellular water-specific MR of microbead-adherent cells: the HeLa cell intracellular water exchange lifetime. NMR Biomed 2008, 21:159-164.

55. Nakagawa M, Miyati T, Hayashi T, Kanao S, Taniguchi M, Higashimura K, Toi M, Togashi $\mathrm{K}$ : Triexponential diffusion analysis in invasive ductal carcinoma and fibroadenoma. Nihon Hoshasen Gijutsu Gakkai Zasshi 2014, 70:199-205.

56. Tanner JE: Transient diffusion in a system partitioned by permeable barriers. Application to NMR measurements with a pulsed field gradient. J Chem Phys 1978, 69:1748-1754.

57. Latour LL, Mitra PP, Kleinberg RL, Sotak CH: Time dependent diffusion coefficients of fluids in porous media as a probe of surface to volume ratio. I. Magn Reson Series A 1993, 101:342-346.

58. Song YQ, Ryu S, Sen PN: Determining multiple length scales in rocks. Nature 2000, 406:178-181.

59. Cheng Y, Cory DG: Multiple scattering by NMR J. Am Chem Soc 1999, 121:7935-7936.

60. Mitra PP, Sen PN, Schwartz LM: Short-time behavior of the diffusion coefficient as a geometrical probe of porous media. Phys Rev 1993, 47:8565-8574.

61. Trampel R, Schiller J, Naji L, Stallmach F, Kärger J, Arnold K: Self-diffusion of polymers in cartilage as studied by pulsed field gradient NMR. Biophys Chem 2002, 97:251-260.

62. Lawrence $L$, Latour LL: Time dependent diffusion of water in a biological model system. Proc Natl Acad Sci 1994, 91:1229-1233.

63. Kärger I, Pfeifer H, Heink W: Principles and Application of Self-Diffusion Measurements by Nuclear Magnetic Resonance. In Advanced in Magnetic and Optical Reconance. Edited by Warren WS. San Diego, CA: Academic; 1988:1-89.

64. Le Bihan D, Turner R, Douek P, Patronas N: Diffusion MR imaging: clinical applications. Am J Roentgenol 1992, 159:591-599.

65. Sen PN: Diffusion and tissue microstructure. J Phys Condens Matter 2004, 16:5213-5220.

66. Ko ES, Han BK, Kim RB, Cho EY, Ahn S, Nam SJ, Ko EY, Shin JH, Hahn SY: Apparent diffusion coefficient in estrogen receptor-positive invasive ductal breast carcinoma: correlations with tumor-stroma ratio. Radiology 2014, 271:30-37.

67. Beaulieu C, Allen PS: Determinants of anisotropic water diffusion in nerves. Magn Reson Med 1994, 31:394-400.

68. Volke F, Eisenblätter S, Galle J, Klose G: Dynamic properties of water at phosphatidylcholine lipid-bilayer surfaces are seen by deuterium and pulsed field gradient proton NMR. Chem Phys Lipids 1994, 70:121-131.

69. Kimmich R, Noack F: Nuclear magnetic relaxation in solutions of proteins and polypeptides. Ber Bunsenges Phys Chem 1971, 75:269-272.

70. Kropman MF, Bakker HJ: Dynamics of water molecules in aqueous salvation shells. Science 2001, 291:2118-2120.
71. Weibel ER, Stäubli W, Gnägi HR, Hess FA: Correlated morphometric and biochemical studies on the liver cell. I. Morphometric model, stereologic methods, and normal morphometric data for rat liver. J Cell Biol 1969, 42:68-91.

72. Sehy JV, Ackerman JJ, Neil JJ: Water and lipid MRI of the Xenopus oocyte. Magn Res Med 2001, 46:900-906.

73. Geil B, Feiweier T, Pospiech E-M, Eisenblatter J, Fujara F, Winter R: Relating structure and translational dynamics in aqueous dispersions of monoolein. Chem and Phys Lipids 2000, 106:115-126.

74. Filippov A, Oradd G, Lindblom G: Influence of cholesterol and water content on phospholipid lateral diffusion in bilayers. Langmuir 2003 19:6397-6400.

75. Fossel ET, Carr JM, McDonagh J: Detection of malignant tumors. Watersuppressed proton nuclear magnetic resonance spectroscopy of plasma. N Engl J Med 1986, 315:1369-1376.

76. Jagannathan NR, Singh M, Govindaraju V, Rangunathan P, Coshic O, Julka PK, Rath GK: Volume localized in vivo proton MR spectroscopy of breast carcinoma: variation of water-fat ratio in patients receiving chemotherapy. NMR Biomed 1998, 11:414-422.

77. Eyal E, Degani H: Model-based and model-free parametric analysis of breast dynamic-contrast-enchanced MRI. NMR Biomed 2009, 22:40-53.

78. Alexander-Williams J, Keighley MR: Assessing the problem, preparing the patient, and minimizing the risks in rectal cancer surgery. World J Surg 1982, 6:510-516.

79. Sinha S, Sinha U, Lucas-Quesada F, Debruhl N, Englander S, Schnall M: Perfusion and diffusion contributions to ADC: application to breast tumors in-vivo. Proc Int/ Soc Mag Reson Med 2001, 9:2331-2331.

80. Griseri $P$, Pagès $G$ : Control of pro-angiogenic cytokine mRNA half-life in cancer: the role of $\mathrm{AU}$-rich elements and associated proteins. J Interferon Cytokine Res 2014, 34:242-254.

81. Westra C, Dialani V, Mehta TS, Eisenberg RL: Using $T_{2}$-weighted sequences to more accurately characterize breast masses seen on MRI. Am J Roentgenol 2014, 202:W183-W190.

82. Partridge SC, Singer $L$, Sun R, Wilmes $\sqcup$, Klifa CS, Lehman CD, Hylton NM: Diffusion-weighted MRI: influence of intravoxel fat signal and breast density on breast tumor conspicuity and apparent diffusion coefficient measurements. Magn Reson Imaging 2011, 29:1215-1221.

doi:10.1186/1756-0500-7-887

Cite this article as: Baikeev et al:: Dynamic properties of water in breast pathology depend on the histological compounds: distinguishing tissue malignancy by water diffusion coefficients. BMC Research Notes 2014 7:887

\section{Submit your next manuscript to BioMed Central and take full advantage of:}

- Convenient online submission

- Thorough peer review

- No space constraints or color figure charges

- Immediate publication on acceptance

- Inclusion in PubMed, CAS, Scopus and Google Scholar

- Research which is freely available for redistribution 